\title{
Karen Vogel
}

Terapia de aceitação e compromisso no tratamento da fobia de espaços fechados: ensaio clínico randomizado.

Dissertação apresentada à Faculdade de Medicina da Universidade de São Paulo para obtenção do título de Mestre em Ciências

Programa de Psiquiatria

Orientador: Prof. Francisco Lotufo Neto 
Dados Internacionais de Catalogação na Publicação (CIP)

Preparada pela Biblioteca da

Faculdade de Medicina da Universidade de São Paulo

Creprodução autorizada pelo autor

Vogel, Karen

Terapia de aceitação e compromisso no tratamento da fobia de espaços fechados: ensaio clínico randomizado / Karen Vogel -- São Paulo, 2014.

Dissertação (mestrado)--Faculdade de Medicina da Universidade de São Paulo. Programa de Psiquiatria.

Orientador: Francisco Lotufo Neto.

Descritores: 1.Terapia de aceitação e compromisso 2.Terapia comportamental 3.Transtornos fóbicos 4 .Imagem por ressonância magnética 5. Ensaio clínico controlado aleatório

USP/FM/DBD-360/14 
Agradecimentos

Agradeço a Deus por ter colocado as seguintes pessoas em meu caminho:

Francisco Lotufo, por confiar em mim e neste trabalho, por sua amabilidade e exemplo de profissional que me inspirou para evoluir.

Meus pais, Alfredo Vogel e Luzia Maria Vogel, por todo amor e por me conduzirem sempre pelos melhores caminhos.

Aloysio Camargo, sua ajuda e apoio foram muito significativos para que eu pudesse ser hoje uma psicóloga clínica.

Mariângela Savoia, Marcia Scazufca e Felipe Corchs, pelas sugestões de melhoria do trabalho.

Michaele Saban, por sua amizade, parceria e companhia nos aprendizados sobre a ACT e na escuta das gravações dos tratamentos.

Heidi Blanche Meyer Pflug, por me conduzir ao caminho da verdade, da luz e do amor.

Às queridas Maria Lucia Rossi e Cristiane Maluhy Gebara pela amizade e torcida.

Pedro Gordon, pela ajuda na etapa da triagem e redação do artigo.

Clarice Gorenstein e Geraldo Buzzatto, pela permissão ao uso do simulador.

Aos participantes do estudo, por confiarem e saírem de suas zonas de conforto. 
Resumo

Vogel, Karen. Terapia de Aceitação e Compromisso no tratamento da fobia de espaços fechados: ensaio clínico randomizado. [Dissertação] São Paulo: Faculdade de Medicina da Universidade de São Paulo; 2014.

Os exames de Ressonância Magnética vêm sendo muito requisitados nas diferentes especialidades médicas como complemento diagnóstico e acompanhamento evolutivo de diversas patologias. Embora seja um método diagnóstico de excelência, os pacientes que se submetem ao exame podem apresentar muito desconforto em razão do espaço restrito do aparelho. A fobia de espaços fechados é considerada um tipo de fobia específica, segundo o Manual Diagnóstico e Estatístico de Transtornos Mentais DSM 5 (APA, 2013). OBJETIVOS: Verificar se uma sessão de Terapia de Aceitação e Compromisso é tão eficaz quanto sete sessões deste mesmo modelo terapêutico no tratamento de pacientes com medo de realizar exames de Ressonância Magnética. MÉTODO: Foi realizado um ensaio clínico randomizado com dois grupos paralelos, um grupo recebeu uma sessão e o outro grupo recebeu sete sessões de tratamento de Terapia de Aceitação e Compromisso. Os participantes foram avaliados no início e ao final do tratamento a partir dos seguintes instrumentos: Inventário de Claustrofobia de Rachman e Taylor (1993), Inventário de Depressão de Beck et al. (1961) e Inventário de Ansiedade estado-traço de Spielberger, Gorsuch e Lushene (1970). O estudo foi realizado em um hospital público na cidade de São Paulo com 30 pacientes. Desfecho principal: permanecer dentro de um simulador de Ressonância Magnética por, no mínimo, trinta minutos após o término de cada um dos tratamentos. Desfechos secundários: as diferenças nos escores dos Inventários de Claustrofobia, Inventário de Depressão de Beck e Inventário de Ansiedade Estado-traço do início e do final do tratamento. RESULTADOS: $92,9 \%$ dos participantes $(\mathrm{N})$ do grupo de sete sessões conseguiram realizar exame de Ressonância Magnética no simulador após o tratamento, enquanto que $50 \%$ dos participantes do grupo de uma sessão conseguiram realizar o exame no simulador $(p=0,033)$. Dos sujeitos que tiveram melhor resposta ao tratamento, $78 \%$ eram do sexo masculino, $80 \%$ eram casados, $78 \%$ não faziam uso de medicação psiquiátrica e em relação ao diagnóstico, $20 \%$ deles tinham diagnóstico de fobia específica de Ressonância Magnética e $80 \%$ deles tinham diagnóstico de fobia de espaços fechados. Todos os sujeitos portadores do diagnóstico Fobia específica de realizar exames de Ressonância Magnética conseguiram realizar o exame no simulador independente do número de sessões. Já os portadores de fobia de espaços fechados responderam mais ao tratamento de sete sessões $(92 \%, p=0.009)$. O inventário de claustrofobia evidenciou que os indivíduos do grupo sete sessões responderam ao tratamento $(p=0,002)$ e mostrou diferenças significativas nos escores antes e 
depois do tratamento e que se mantiveram três meses depois. Já no inventário de Beck, observa-se melhora dos sintomas depressivos ao final do tratamento $(p=0,015)$, porém não há diferença após três meses. Observou-se através dos coeficientes de Regressão que quanto maior a pontuação no inventário de claustrofobia e de Depressão de Beck, menor a probabilidade de conseguir permanecer no simulador. Entretanto, fazer pelo menos sete sessões de terapia aumenta a probabilidade do desfecho positivo desejado. $O$ estudo mostrou ainda que sete sessões de terapia foram benéficas, pois mesmo com escores elevados de sintomatologia depressiva os pacientes foram bem sucedidos na realização do exame de Ressonância Magnética no simulador.

Descritores: Terapia de aceitação e compromisso, Terapia comportamental, Transtornos fóbicos, Imagem por ressonância magnética, Ensaio clínico controlado aleatório. 
Abstract

Vogel, Karen. Acceptance and Commitment Therapy to treat phobia of enclosed spaces: a randomized clinical trial. [Dissertation] São Paulo: School of medicine of the University of São Paulo; 2014.

The MRI exams have been in considerable demand in various medical specialties to diagnose diseases. Although it is an effective diagnostic method, patients who are subjected to the exam might present high levels of discomfort due to the confined space of the device. The phobia of enclosed spaces is considered a type of specific phobia, according to the Diagnostic and Statistical Manual of Mental Disorders 5 (APA, 2013). Objectives: to check if a single session of Acceptance and Commitment Therapy is as effective as seven sessions of the same therapeutic model for the treatment of patients with fear of undergoing MRI exams and enclosed spaces phobia. METHODS: A randomized clinical trial study with two parallel groups was performed, one group underwent one session and the other group underwent seven sessions of Acceptance and Commitment Therapy. Participants were assessed at the beginning and at the end of treatment with the following instruments: Claustrophobia Inventory from Rachman and Taylor (1993), Beck Depression Inventory from beck et al. (1961) and Anxiety Inventory State - Trait from Spielberger, Gorsuch and Luschene (1970). The study was performed in a public hospital in the city of Sao Paulo with 30 patients. Main outcome: to remain in a MRI simulator for at least 30 minutes after each treatment. Secondary outcomes: compare the differences in the inventories of Claustrophobia, Beck Depression Inventory and the Anxiety Inventory TraitState scores compared at the beginning and at the end of treatments. RESULTS: $92.9 \%$ of participants $(\mathrm{N})$ on the seven sessions group were able to carry out the MRI exam simulator after treatment, while $50 \%$ of participants of the one session group were able carry out the post treatment session in the simulator $(p=0.033)$. From the participants who had better response to treatment, $78 \%$ were male, $80 \%$ were married, $78 \%$ did not use psychiatric medication and $20 \%$ had a diagnosis of specific MRI phobia, $80 \%$ had a diagnosis of enclosed spaces phobia. All subjects with the Specific Phobia of performing MRI exams diagnosis were able to perform at the simulator test without considering the number of treatment sessions. Those with phobia of enclosed spaces responded more to the seven sessions treatment $(92 \%, p=$ 0.009 ). The inventory of claustrophobia showed that individuals in the seven sessions group performed the treatment $(p=0.002)$, showing significant differences before and after treatment and the level of performance was the same three months later. The Beck Inventory showed that there was 
improvement in depressive symptoms at the end of treatment $(p=0.015)$, but there was no difference after three months. It was observed through the regression coefficients that the higher the score on the inventory of claustrophobia and Beck Depression Inventory, the lower the probability of performing in the simulator. However, doing at least seven sessions of therapy increases the likelihood of the desired positive outcome. The study also showed that seven therapy sessions were beneficial, because even with high scores of depressive symptoms patients were successful in the test of the MRI simulator.

Descriptors: Acceptance and commitment therapy, Behavior therapy, Phobic disorders, Magnetic resonance imaging, Randomized controlled trial. 


\section{LISTA DE TABELAS}

Tabela 1 - Distribuição dos sujeitos, conforme as variáveis biossociodemográficas.

Tabela 2 - Medicações psiquiátricas em uso.

Tabela 3 - Diagnóstico e distribuição dos participantes.

Tabela 4 - Dados biossociodemográficos dos grupos de uma e de sete sessões.

Tabela 5 - Média de idade dos participantes dos grupos A e B.

Tabela 6 - Diagnóstico dos participantes dos grupos A e B, segundo DSM IV (APA, 2002).

Tabela 7 - Desfecho do tratamento dos grupos A e B.

Tabela 8 - Variáveis biossociodemográficas segundo desfechos.

Tabela 9 - Percentual de pacientes que conseguiram realizar o exame no simulador.

Tabela 10 - Escalas $x$ diagnósticos na triagem.

Tabela 11 - Médias dos resultados dos inventários dos grupos uma e sete sessões, antes, depois e pós três meses de tratamento e o $\mathrm{p}$-valor para a comparação da diferença entre médias para cada tempo

Tabela 12 - Comparação entre as médias dos inventários dentro de cada grupo, uma sessão e sete sessões, entre os tempos avaliados.

Tabela 13 - Resultado da Regressão Logística considerando como variável dependente o desfecho (SIM, NÃO), e variável independente o escore do inventário de claustrofobia antes.

Tabela 14 - Resultado da Regressão Logística considerando como variável dependente o desfecho (SIM, NÃO) e variável independente o escore do inventário Beck antes do tratamento. 


\section{LISTA DE FIGURAS}

Figura 1: Diagrama Prisma Flow - Levantamento bibliográfico fobia de espaços fechados e Ressonância Magnética.

Figura 2: Fluxograma com as etapas da pesquisa.

Figura 3: Gráfico: Média e Intervalo de Confiança de 95\% para o Inventário de Claustrofobia segundo as três avaliações. 
LISTA DE SIGLAS E ABREVIATURAS

ACT Acceptance and Commitment Therapy

APA American Psychiatric Association

CAPPESQ Comissão de Ética para Análise de Projetos de Pesquisa

IDATE Inventário de Ansiedade Traço-Estado de Spilberger

RM Ressonância Magnética

SPSS Statistical Package for the Social Sciences 
1. Introdução

1.1. Medo, ansiedade e fobias 1

1.2. O medo de procedimentos médicos 2

1.3. O exame de Ressonância Magnética 2

1.4. Fobias específicas 4

1.4.1. Fobia de espaços fechados 6

1.4.2. O medo de Ressonância Magnética 7

1.5. Levantamento bibliográfico 10

1.6. O tratamento das fobias 13

1.7. Justificativa 22

1.8. Objetivo 23

1.9. Hipóteses 23

2. Método

2.1. Amostra do estudo 24

2.2. Local 24

2.3. Instrumentos 24

2.3.1. Questionário Biossociodemográfico 25

2.3.2. Questionário de Claustrofobia 25

2.3.3. Inventário de Depressão de Beck 26

2.3.4. Inventário de Ansiedade Traço-Estado IDATE 26

2.4. Procedimento 27

2.5. Análise estatística 42

2.6. Aspectos éticos 43

3. Resultados 44

4. Discussão 57

5. Referências Bibliográficas 65

6. Anexos 76 
1. Introdução

\subsection{Medo, ansiedade e fobias}

O medo é uma emoção que leva o indivíduo a se proteger de alguma ameaça ou perigo e tem um importante valor para a sobrevivência humana (Marks, 1987). Sem ele, provavelmente não teríamos sobrevivido aos perigos do ambiente. Como toda emoção, o medo vem associado a uma série de reações corporais e comportamentais. Tais reações podem se manifestar como tremores, taquicardia, entre outros, e reações comportamentais podem se dar através de paralisação ou fuga da situação ou objeto temidos.

Knapp e colaboradores (2004) afirmam que o medo é uma reação filogeneticamente determinada que pode adquirir um caráter não adaptativo e desproporcional, dando origem a psicopatologia. Sendo o medo uma emoção experimentada universalmente, sua simples presença diante de uma determinada situação ou objeto não é suficiente para que seja caracterizada como fobia. Muitas pessoas se sentem temerosas em algumas circunstâncias, por exemplo, diante de um inseto sem, entretanto, apresentarem um quadro fóbico. Para que seja diagnosticado como transtorno fóbico, algumas caraterísticas precisam estar presentes, as quais são descritas no critério do DSM 5 (APA, 2013).

Muitos termos são utilizados como sinônimos de medo: ansiedade, angústia, nervosismo, apreensão, agitação, pânico, entre outros. Segundo Marks (1987), o medo pode ser considerado como sendo uma sensação incômoda que aparece diante de uma situação real de perigo.

Ansiedade, segundo este autor, é uma emoção similar ao medo, mas que aparece sem que a situação real de perigo esteja presente. A ansiedade está diretamente relacionada a três condições: sensação de perigo iminente, espera pelo perigo e desestruturação diante do perigo com sensação de estar desprotegido (Juarez, et al., 2002). Para Nardi (1998), a ansiedade é definida 
como uma sensação de apreensão que pode manifestar-se fisicamente por Meio de: mal-estar gástrico, dor toráxica, palpitações, sudorese, cefaléia,

tontura, falta de ar, tremores, extremidades frias, calafrios, ondas de calor, entre outros. Já a fobia é um medo de uma situação específica que causa uma reação fora de proporção e que leva o indivíduo a evitar o estímulo fóbico.

\subsection{O medo de procedimentos médicos}

Procedimentos diagnósticos, médicos, odontológicos e cirúrgicos podem ser vivenciados com medo extremo. Muitos envolvem respostas de esquiva (Choy, Stein, Hermann, 2013) que impedem o paciente de realizar algum tratamento necessário. Muitos procedimentos são vivenciados com extrema angústia. Exemplos desses procedimentos são as cirurgias, os tratamentos dentários, exames como os de Ressonância Magnética, colonoscopia, endoscopia são alguns exemplos.

Os mesmos autores ressaltam que a ansiedade do procedimento se dá pela apreensão da possibilidade de sofrimento agudo. Esta antecipação do sofrimento pode levar o paciente a interromper o exame ou mesmo nem realizá-lo. Os temores podem ser muitas vezes racionais, como a preocupação de que uma biópsia de mama possa revelar um tumor maligno. Em alguns casos pode ser irracional, como o medo de asfixia durante um exame de ressonância magnética.

\subsection{O exame de Ressonância Magnética}

Com a expansão de novas tecnologias da medicina, o exame de Ressonância Magnética é um dos métodos diagnósticos mais solicitados para investigação de uma série de condições médicas (Medelez e McCrank, 1993). 
Cerca de 80 milhões de procedimentos são realizados por ano em todo o mundo (Enders et al., 2001).

O exame de Ressonância Magnética é uma importante ferramenta de referência diagnóstica. Seu uso iniciou-se na década de 80 . As suas vantagens em relação a outros métodos diagnósticos são: é um método não invasivo, permite imagens detalhadas em alta resolução, apresenta alta especificidade e sensibilidade e é uma tecnologia bastante segura (Amaro e Yamashita, 2001). Apesar de todas essas vantagens, este exame é um recurso diagnóstico de alto custo, apenas grandes centros de diagnóstico dispõem de tal equipamento. Além do custo do equipamento, a sua operacionalização requer uma equipe médica, técnica, administrativa e de apoio, o que contribui para o aumento do custo do procedimento.

O equipamento de Ressonância Magnética foi inventado por Edills Purcell e Felix Bloch, em meados dos anos 40. Em 1952, estes pesquisadores foram laureados com o Prêmio Nobel de Física (Sanches, 2009). O aparelho é semelhante a um cubo gigante, que possui uma entrada no centro do magneto, no sentido horizontal, onde o indivíduo é posicionado em uma mesa específica que desliza para o interior do imã (magneto). Os tipos de equipamentos mais utilizados são: o com as laterais abertas, que permite um ambiente menos fechado e o equipamento fechado, onde é possível observar o ambiente externo somente pela abertura central. $\mathrm{O}$ aparelho com posicionamento vertical é mais recente e já vem sendo utilizado, porém este faz apenas imagens de alguns segmentos corporais. (Silva, 2013)

Dependendo da indicação e da hipótese diagnóstica, o exame de Ressonância Magnética requer contraste endovenoso. Este procedimento tem como objetivo analisar a perfusão tecidual, identificar tumores, trombos, fibroses, infartos e alterações de estruturas, como a cardíaca por exemplo. (Torpy et at., 2009). O uso do contraste também causa ansiedade no paciente, principalmente para aqueles que temem injeções, sangue e outros procedimentos médicos.

Para a realização do exame de Ressonância Magnética, é solicitado que - paciente permaneça imóvel durante trinta minutos até uma hora, 
aproximadamente. Algumas situações podem prejudicar a realização do exame como movimentações corporais e de respiração. O término prematuro do exame também pode se dar por razões como ansiedade ou o desconforto do paciente.

\subsection{As fobias específicas}

As fobias específicas têm, segundo o DSM 5 (APA, 2014), as seguintes características: medo acentuado e persistente revelado pela presença ou antecipação de um objeto ou situação fóbica (critério A); a exposição ao estímulo fóbico provoca, invariavelmente, uma resposta imediata de medo ou ansiedade (critério B); a situação fóbica é evitada ou suportada com intensa ansiedade (critério C); o indivíduo reconhece que o medo é excessivo e irracional (critério D); o medo, a ansiedade e a esquiva da situação são persistentes em geral por seis meses ou mais (critério E); o medo, a ansiedade e a esquiva da situação causam desconforto, interferindo na rotina do indivíduo, alterando seu funcionamento ocupacional e vida social (critério F); o transtorno não é melhor explicado por outro transtorno mental, incluindo medo, ansiedade e esquiva das situações como no caso dos sintomas de transtornos de pânico, objetos ou situações relacionados a obsessões, como no transtorno obsessivo compulsivo, lembranças de eventos traumáticos, como no transtorno pós traumático, separação da casa e das figuras de apego, como na ansiedade de separação, ou situações sociais, como na fobia social (critério G).

O mesmo manual classifica as fobias específicas a partir dos seguintes critérios:

Animal (ex: aranhas, insetos, cachorros, entre outros)

Ambiente natural (ex: altura, trovões, água)

Sangue, injeção, ferimentos (ex: medo de sangue, medo de injeções e transfusões, medo de outros procedimentos médicos, medo de se machucar).

Situacional (ex: aviões, elevadores, locais fechados). 
Outros (ex: situações que levam a sensação de sufocamento ou asfixia, medo de vomitar, de sons altos, de personagens vestindo fantasias).

As fobias estão entre os transtornos mentais mais frequentes nas áreas urbanas. Uma revisão da literatura mostrou que 6,2\% a 15,5\% das pessoas apresentaram ao menos um tipo de fobia e as mulheres possuíam prevalência maior (Fredrikson et al., 1996). Dos estímulos que mais medos produzem, dois são os mais prevalentes: o medo de altura e de espaços fechados (Gouveia, Medeiros, Gouveia, Santos, Diniz, 2008).

Nos Estados unidos, a prevalência estimada para fobias específicas é de 7 a 9\% (APA, 2013). As prevalências nos países da Europa são similares a dos Estados Unidos (6\%), mas nos países asiáticos, africanos e na América Latina, as taxas são menores, variando de 2 a 4\%. (APA, 2013). No Brasil, um único estudo na cidade de Porto Alegre mostrou prevalência estimada de 12,8\% (Busnello et al., 1992).

As fobias geralmente se desenvolvem na infância, antes dos 10 anos e a média de idade do início varia entre 7 a 11 anos (Barlow, 2002). A prevalência é de $5 \%$ em crianças e $16 \%$ em pessoas de 13 a 17 anos. Em relação aos homens, as mulheres sofrem com os transtornos fóbicos na proporção de dois para um. As fobias de animais, de ambientes naturais e situacionais são as mais comuns em mulheres, enquanto que as do tipo sangue-injeção-ferimentos são experimentadas igualmente pelos dois sexos.

É comum encontrarmos indivíduos com um número múltiplo de fobias. Segundo o DSM-5, setenta e cinco por cento das pessoas que sofrem de fobia específica temem mais de uma situação ou objeto. Por exemplo, se uma pessoa teme trovões e voar, então dois tipos de diagnósticos são necessários: fobia específica do tipo ambiente natural e fobia específica do tipo situacional. Estima-se que $50 \%$ a $80 \%$ das pessoas que sofrem de fobias específicas apresentam outras comorbidades psiquiátricas (Terra et al., 2007).

O estresse associado às fobias, principalmente se não reconhecido, pode contribuir para outras complicações psiquiátricas como outros transtornos de ansiedade, de humor ou transtornos associados ao uso de substâncias 
psicoativas. Há evidências de que muitos abusadores de substâncias começam a usar medicações para aliviar um transtorno de ansiedade, que poderia ser uma fobia (Kessler et al., 1996).

Apesar das fobias serem frequentes na população e apresentarem boa melhora terapêutica, os pacientes raramente procuram tratamento (Barlow, 2002). Estes indivíduos muitas vezes são tratados para outros tipos de transtornos de ansiedade, como Transtorno de Pânico, Transtorno Obsessivo Compulsivo e Fobia Social, e o diagnóstico de fobias específicas é considerado secundário (Antony, et al., 1994).

Algumas hipóteses sobre a origem das fobias resultam da integração das abordagens etológicas, biológicas e da aprendizagem (Hollander e Simeon, 2004). Fyer e colaboradores (1990) encontraram alta transmissão familiar nas fobias específicas, com risco aproximadamente três vezes maior para familiares de primeiro grau das pessoas afetadas. Em estudo de fobia em gêmeos, Kendler et al. (1992) determinaram que a responsabilidade da agregação familiar da fobia foi, em grande parte, por fatores genéticos.

Os mesmos autores também enfatizaram que os fatores ambientais desempenharam um papel importante no desenvolvimento dos transtornos fóbicos. As fobias podem iniciar após eventos traumáticos, como acidentes, desastres naturais, doenças, pela observação de outros indivíduos em situações traumáticas, entre outros. Pode-se ainda desenvolver fobias a partir de extensa divulgação de conteúdo catastrófico na mídia, como é o caso de desastres aéreos ou naturais.

\subsubsection{Fobia de espaços fechados}

Conhecida como fobia específica do tipo situacional, a fobia de espaços fechados ou claustrofobia é um medo que está associado à esquiva de objetos e situações de asfixia, restrição de movimentos e confinamento, o que atrapalha a vida da pessoa ou the traz sofrimento. Esta condição é agravada 
nos centros urbanos, onde há necessidade de compartilhar espaços pequenos com um número cada vez maior de pessoas, como elevadores, moradias, transportes públicos, aviões, túneis congestionados, entre outros.

A fobia de espaços fechados é também encontrada em publicações sobre agorafobia, o que pode prejudicar um estudo aprofundado sobre o tema (Ost, 2006). Apesar dessa associação entre as duas fobias, na agorafobia o medo está relacionado ao receio de passar mal ou não receber socorro adequado em diversos contextos como multidões ou locais públicos.

Aproximadamente $10 \%$ da população têm algum incômodo em espaços fechados e $2 \%$ sofrem desta fobia de forma grave. Dos indivíduos que apresentam esta fobia de forma grave, em 33\% o início foi na infância (Rachman e Taylor, 1993).

As manifestações de fobia de espaços fechados mais frequentes são o medo de utilizar elevadores e o medo de voar de avião (Chapman, 1997). Martinez et al. (2003) ressaltam que algumas pessoas temem espaços fechados pelo que pode ocorrer nessas situações caso tenham que permanecer nesses lugares, como receio de não conseguir sair da situação ou medo de não conseguir respirar. $O$ temor de que não haverá ar suficiente para respirar é um dos pensamentos mais presentes nesses pacientes (Kirkpatrick, 1984).

\subsubsection{O medo de Ressonância Magnética}

Para os indivíduos com fobia de espaços fechados, a realização de exames de Ressonância Magnética pode ser vivenciada com extrema ansiedade e incômodo. Medo de ficar restrito em um local fechado, a necessidade de permanecer imobilizado, receio de ser machucado, medo do desconhecido, medo da perda de controle, apreensão sobre o resultado diagnóstico do exame, receio do contraste, estão entre os medos mais relatados sobre a realização do procedimento. (Katz, Wilson e Frazer, 1994). 
Manifestações corporais como tensão, nervosismo, irritabilidade, preocupação e apreensão são relatados por estas pessoas antes e durante a realização do procedimento. (Margis et al., 2003).

Reações de ansiedade foram frequentemente reportadas pelos pacientes que se submetem ao exame de Ressonância Magnética, mesmo em pessoas que não possuíam sintomas de fobia de espaços fechados. Os índices de apreensão foram evidenciados em $35 \%$ dos pacientes e medo severo em torno de 05 a 10\% dos pacientes (Phillips e Deary, 1995). Vinte por cento dos pacientes que foram submetidos ao exame não conseguiram concluí-lo (Klonoff et al, 1986) e $2 \%$ a $14,3 \%$ dos pacientes necessitaram estar sedados para a realização do procedimento (Murphy e Brunberg, 1994).

A realização da Ressonância Magnética está associada a sofrimento psicológico muito intenso para alguns indivíduos. Kilborn e Labbe (1990) apresentam um estudo que apontou que $9,6 \%$ das pessoas submetidas ao exame apresentaram aumento de ansiedade ao realizar novos exames. Fishbain et al. (1989) mostraram que pacientes sem história prévia de fobia de espaços fechados passaram a desenvolver o transtorno após a realização do exame.

Os pacientes que vivenciam altos índices de ansiedade geralmente realizam o exame com o uso de sedação. No entanto, a sedação pode causar riscos a depender da droga ministrada, do grau de sedação, da idade e as condições físicas do paciente. Além disso, efeitos colaterais como sonolência, confusão mental, náusea e vômitos também contribuem para uma resistência ao uso deste tipo de procedimento antes do exame (Marshall et al., 2007).

Devido às consequências que o uso da sedação pode causar no paciente, o desenvolvimento de técnicas alternativas para a realização de procedimentos com Ressonância Magnética vêm sendo pesquisadas ao longo das décadas (Wood e Mcglynn, 2000; Granet e Gelber, 1990; Weinreb et al., 1984; Shellock e Kanal, 1994; Slifer et al., 1991; Velloso et al., 2010; GarciaPalacios et al., 2007). 
Grande parte destas intervenções tem como objetivo reduzir o desconforto e a ansiedade dos pacientes que são submetidos a exames de Ressonância Magnética. Tais intervenções envolvem o uso de procedimentos de exposição e relaxamento, hipnose, deitar de bruços, uso de ventiladores para movimentação do ar, presença de familiares, realização do exame com luz acesa e intensa, uso de botão de pânico, distração através de música, distração através de realidade virtual e uso de informativo prévio sobre as características do exame como procedimentos alternativos ao uso da sedação.

Pesquisas sobre o uso alternativo à sedação (Garcia-Pallacios et al., 2007, Kilborn e Labbe, 1990 e Klonoff et al., 1986) apontam para necessidade de procedimentos breves, uma vez que o paciente anseia por fazer o exame e para que o início de um eventual tratamento seja imediato. Além disso, a opção pelo tratamento breve também se justifica por questões institucionais e financeiras como honorários profissionais, por exemplo.

Pelo fato de equipamentos de ressonância magnética serem ameaçadores para alguns indivíduos, foram criados aparelhos simuladores de RM para preparar as pessoas para o exame (Ball e Holland, 2009), além de identificar participantes que pudessem desenvolver sintomas claustrofóbicos (Eshed et al., 2007; McGlynn et al., 2001; Thorpe et al., 2008).

Este tipo de simulador tem sido utilizado em centros de pesquisa em neuropsiquiatria, para preparar crianças para exames de Ressonância Magnética estrutural do crânio sem que seja necessária sedação farmacológica (Rosenberg et al., 1997). Em pesquisa também se treinam as tarefas necessárias no simulador. A estrutura montada replica o ambiente de uma sala de RM, cujo cenário construído inclui o arcabouço do equipamento com tubo, bobina de crânio e mesa móvel, assim como aparelhagem para a reprodução do som replicando de forma fiel os diversos tipos de ruídos de um equipamento de RM em funcionamento. Este simulador permite que o indivíduo seja deitado dentro do tubo com sua cabeça imóvel, escutando ruídos semelhantes aos produzidos pelo equipamento de RM. 
1.5 Levantamento bibliográfico

O levantamento bibliográfico deste trabalho foi realizado no segundo semestre de 2012, a partir das pesquisas realizadas nas bases de dados PUBMED, LILACS e PsycINFO. Inicialmente, utilizaram-se as palavras chave specific phobias e magnetic resonance, cujo resultado foi incipiente. Outra pesquisa, desta vez com as palavras fear e magnetic resonance, anxiety e magnetic resonance resultaram mais de duas mil publicações cada uma. Uma nova pesquisa com as palavras chave claustrophobia e magnetic resonance evidenciaram publicações que tinham relação com o presente estudo.

As equações booleanas foram as seguintes:

specific[All Fields] AND ("phobic disorders"[MeSH Terms] OR ("phobic"[All Fields] AND "disorders"[All Fields]) OR "phobic disorders"[All Fields] OR "phobias"[All Fields]) AND ("magnetic resonance spectroscopy"[MeSH Terms] OR ("magnetic"[All Fields] AND "resonance"[All Fields] AND "spectroscopy"[All Fields]) OR "magnetic resonance spectroscopy"[All Fields] OR ("magnetic"[All Fields] AND "resonance"[All Fields]) OR "magnetic resonance"[All Fields])

("phobic disorders"[MeSH Terms] OR ("phobic"[All Fields] AND "disorders"[All Fields]) OR "phobic disorders"[All Fields] OR "claustrophobia"[All Fields]) AND ("magnetic resonance spectroscopy"[MeSH Terms] OR ("magnetic"[All Fields] AND "resonance"[All Fields] AND "spectroscopy"[All Fields]) OR "magnetic resonance spectroscopy"[All Fields] OR ("magnetic"[All Fields] AND "resonance"[All Fields]) OR "magnetic resonance"[All Fields])

O diagrama a seguir representa o fluxograma PRISMA do levantamento bibliográfico realizado: 


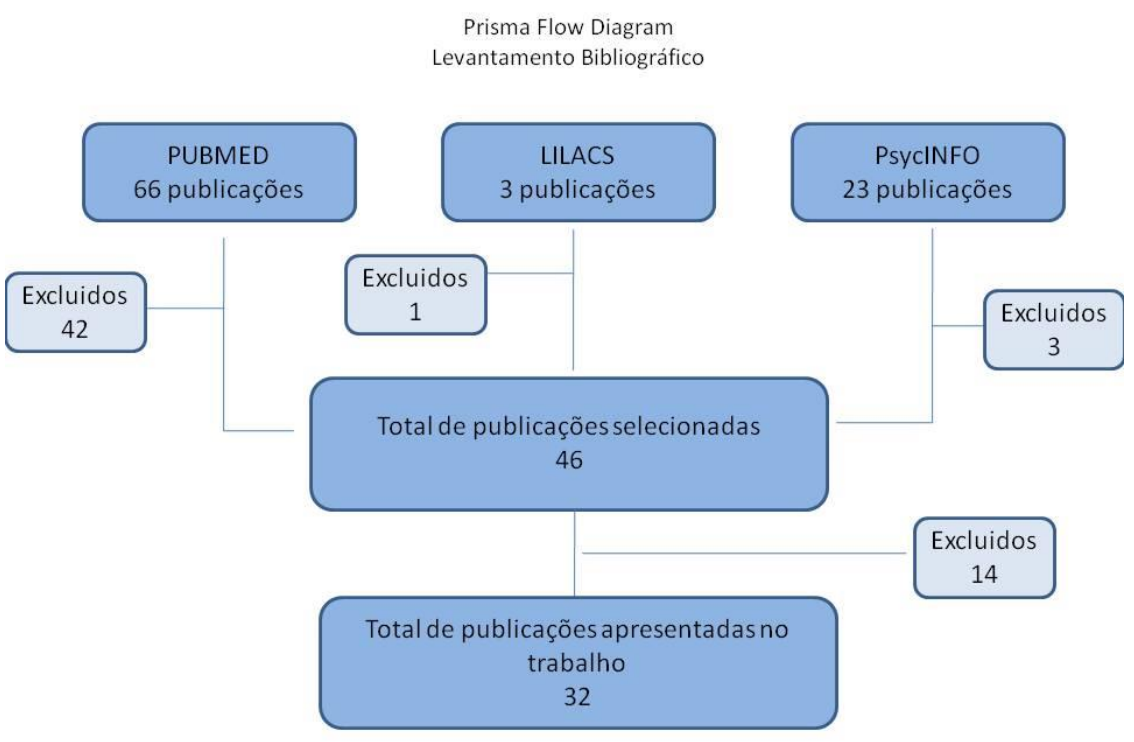

FIGURA 1: Diagrama Prisma Flow - Levantamento bibliográfico fobia espaços fechados e Ressonância Magnética

O total de 92 publicações foram levantadas e lidas nas bases de dados PUBMED, LILACS e PsycINFO. Primeiramente, foram excluídas 46 publicações por duplicidade e não relevância ao tema. Das 46 publicações restantes, 14 foram excluídas por não apresentarem dados ou informações relacionadas à fobia de espaços fechados e exames de Ressonância Magnética. Por fim, 32 publicações foram utilizadas na introdução do presente trabalho.

Das publicações utilizadas neste levantamento, $82 \%$ delas tratam de artigos sobre métodos para diminuição dos níveis de ansiedade do paciente tais como: hipnose, realidade virtual, movimentação do ar, presença de acompanhantes, relaxamento, distração, entre outros. Oito por cento das publicações dizem respeito à descrição do medo de procedimentos médicos e às suas implicações. Dez por cento das publicações são descrições epidemiológicas das fobias e seus fatores determinantes. As trinta e duas referências bibliográficas utilizadas estão representadas na seguinte tabela: 


\begin{tabular}{|c|c|c|}
\hline Autor & Título & Descrição \\
\hline $\begin{array}{l}\text { Amaro Jr e Yamashita } \\
\text { (2001) }\end{array}$ & 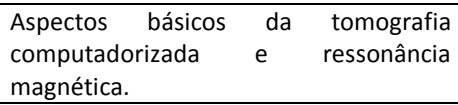 & $\begin{array}{l}\text { Descrição fobia e suas } \\
\text { implicações }\end{array}$ \\
\hline Ball e Holland (2009) & $\begin{array}{l}\text { The fear of new technology: a naturally } \\
\text { occurring phenomenon }\end{array}$ & $\begin{array}{l}\text { Descrição fobia e suas } \\
\text { implicações }\end{array}$ \\
\hline Busnello et al. (1992) & $\begin{array}{l}\text { Morbidade psiquiátrica na população } \\
\text { urbana de Porto Alegre }\end{array}$ & Epidemiologia \\
\hline Choy et al. (2013) & $\begin{array}{l}\text { Acute procedure anxiety in adults: } \\
\text { course, screening, assessment and } \\
\text { differential diagnosis }\end{array}$ & $\begin{array}{l}\text { Descrição fobia e suas } \\
\text { implicações }\end{array}$ \\
\hline Enders et al. (2001) & $\begin{array}{l}\text { Reduction of claustrophobia during } \\
\text { magnetic resonance imaging: methods } \\
\text { and design of the claustrophobic } \\
\text { randomized trial. }\end{array}$ & Opções de tratamento \\
\hline Eshed et al. (2007) & $\begin{array}{l}\text { Claustrophobia and premature } \\
\text { termination of magnetic resonance } \\
\text { imaging examinations }\end{array}$ & $\begin{array}{l}\text { Descrição fobia e suas } \\
\text { implicações }\end{array}$ \\
\hline Fishbain et al. (1989) & $\begin{array}{l}\text { MR Imaging as a trigger for persistent } \\
\text { claustrophobia }\end{array}$ & $\begin{array}{l}\text { Descrição fobia e suas } \\
\text { implicações }\end{array}$ \\
\hline Fyer et al. (1990) & $\begin{array}{l}\text { Familial transmission of simple phobias } \\
\text { and fears: preliminary report. }\end{array}$ & $\begin{array}{l}\text { Descrição fobia e suas } \\
\text { implicações }\end{array}$ \\
\hline $\begin{array}{l}\text { Garcia-Pallacios et al. } \\
\text { (2007) }\end{array}$ & $\begin{array}{l}\text { Use of virtual reality distraction to } \\
\text { reduce Claustrophobia symptoms during } \\
\text { mock magnetic resonance imaging brain } \\
\text { scan: a case report. }\end{array}$ & Opções de tratamento \\
\hline Granet e Gelber (1990) & Claustrophobia during MR imaging. & $\begin{array}{l}\text { Descrição fobia e suas } \\
\text { implicações }\end{array}$ \\
\hline Gouveia et al. (2008) & Cuestionario de Claustrofobia & Epidemiologia \\
\hline Katz et al. (1994) & $\begin{array}{l}\text { Anxiety and its determinants in patients } \\
\text { undergoing magnetic resonance } \\
\text { imaging. }\end{array}$ & Opções de tratamento \\
\hline Kendler et al. (1992) & $\begin{array}{l}\text { The genetic epidemiology of phobias in } \\
\text { woman: the interrelationship of } \\
\text { agoraphobia, social phobia, situational } \\
\text { phobia and simple phobia. }\end{array}$ & Epidemiologia \\
\hline Kilborn e Labbe (1990) & $\begin{array}{l}\text { Magnetic resonance imaging scanning } \\
\text { procedures: development of phobic } \\
\text { response during scan and at one month } \\
\text { follow up. }\end{array}$ & Opções de tratamento \\
\hline Kirkpatrik (1994) & $\begin{array}{l}\text { Age, gender and patterns of intense fear } \\
\text { among adults }\end{array}$ & Epidemiologia \\
\hline Klonoff et al. (1986) & $\begin{array}{l}\text { The use of systematic desensitization to } \\
\text { overcome resistance to magnetic } \\
\text { resonance imaging }\end{array}$ & Opções de tratamento \\
\hline Marshall et al. (2007) & $\begin{array}{l}\text { A comprehensive analysis of MRI } \\
\text { research risks: in support of full } \\
\text { disclosure }\end{array}$ & Opções de tratamento \\
\hline McGlynn et al. (2001) & $\begin{array}{l}\text { Component fears of claustrophobia } \\
\text { associated with mock magnetic } \\
\text { resonance imaging. }\end{array}$ & $\begin{array}{l}\text { Descrição fobia e suas } \\
\text { implicações }\end{array}$ \\
\hline $\begin{array}{l}\text { Medelez e McCranck } \\
(1990)\end{array}$ & $\begin{array}{l}\text { Anxiety-related reactions associated } \\
\text { with Magnetic Resonance Imaging } \\
\text { examinations. }\end{array}$ & $\begin{array}{l}\text { Descrição fobia e suas } \\
\text { implicações }\end{array}$ \\
\hline $\begin{array}{l}\text { Murphy e Brunberg } \\
\text { (1997) }\end{array}$ & $\begin{array}{l}\text { Adult claustrophobia, anxiety and } \\
\text { sedation MRI. }\end{array}$ & $\begin{array}{l}\text { Descrição fobia e suas } \\
\text { implicações }\end{array}$ \\
\hline
\end{tabular}




\begin{tabular}{|c|c|c|}
\hline Ost et al. (1989) & $\begin{array}{l}\text { Applied tension, applied relaxation and } \\
\text { the combinations in the treatment of } \\
\text { blood phobia }\end{array}$ & $\begin{array}{l}\text { Descrição fobia e suas } \\
\text { implicações }\end{array}$ \\
\hline $\begin{array}{l}\text { Rachman e Taylor } \\
\text { (1993) }\end{array}$ & Analyses of Claustrophobia & Epidemiologia \\
\hline Radomsky et al. (2001) & The claustrophobic questionnaire. & $\begin{array}{l}\text { Descrição fobia e suas } \\
\text { implicações }\end{array}$ \\
\hline Rosenberg et al. (1997) & $\begin{array}{l}\text { Magnetic Resonance imaging of children } \\
\text { without sedation: preparation with } \\
\text { simulation }\end{array}$ & Opções de tratamento \\
\hline Sanches (2009) & $\begin{array}{l}\text { Sobreposição de imagens de tomografia } \\
\text { e Ressonância Magnética: uma nova } \\
\text { modalidade de imagens médica } \\
\text { tridimensional }\end{array}$ & $\begin{array}{l}\text { Descrição fobia e suas } \\
\text { implicações }\end{array}$ \\
\hline Shellock, Kanal (1994) & $\begin{array}{l}\text { Magnetic Resonance: bioeffects, safety } \\
\text { and patient management. }\end{array}$ & $\begin{array}{l}\text { Descrição fobia e suas } \\
\text { implicações }\end{array}$ \\
\hline Silva (2013) & $\begin{array}{l}\text { Validação do questionário de } \\
\text { claustrofobia em pacientes submetidos } \\
\text { à ressonância magnética }\end{array}$ & $\begin{array}{l}\text { Descrição fobia e suas } \\
\text { implicações }\end{array}$ \\
\hline Thorpe et al. (2008) & $\begin{array}{l}\text { A Claustrophobia in MRI: the role of } \\
\text { cognitions }\end{array}$ & $\begin{array}{l}\text { Descrição fobia e suas } \\
\text { implicações }\end{array}$ \\
\hline Torpy et al. (2009) & Magnetic Resonance Imaging & Epidemiologia \\
\hline Velloso et al. (2010) & $\begin{array}{l}\text { Hipnose para controle de claustrofobia } \\
\text { em exames de ressonância Magnética }\end{array}$ & Opções de tratamento \\
\hline Weinreb et al. (1984) & $\begin{array}{l}\text { Magnetic resonance imaging: improving } \\
\text { patient tolerance and safety. }\end{array}$ & Opções de tratamento \\
\hline Wood e Mcglynn (2000) & $\begin{array}{l}\text { Research on Post treatment return of } \\
\text { claustrophobic fear, arousal and } \\
\text { avoidance using mock diagnostic } \\
\text { imaging. }\end{array}$ & Opções de tratamento \\
\hline
\end{tabular}

\subsection{O Tratamento das fobias}

O tratamento das fobias iniciou-se na década de 20 do século passado, a partir de um estudo que ficou conhecido mundialmente como o caso do "Pequeno Albert". Neste experimento, John Watson utilizou os princípios do condicionamento respondente, anteriormente só aplicado em animais (Costa, 2002). No experimento, Watson tentou determinar se era possível condicionar o medo de um animal em uma criança através da apresentação simultânea do animal a um ruído alto e assustador. Além disso, procurou também observar se o medo condicionado poderia ser transferido para outros animais ou objetos. $O$ procedimento foi alvo de muitas críticas, principalmente pelos aspectos éticos envolvidos. 
O Behaviorismo estava, nesta época, despontando como modo de estudar o comportamento a partir do desenvolvimento do paradigma do condicionamento respondente. O termo reflexo condicionado passa a ser evidenciado a partir das pesquisas do fisiologista russo Ivan Pavlov, e pode ser enunciado da seguinte forma: se um estímulo neutro for pareado um certo número de vezes a um estímulo eliciador, este estímulo, previamente neutro, irá evocar a mesma espécie de resposta (Keller, 1973).

Watson, que era nesta época presidente da American Psychological Association, anunciou que os métodos de condicionamento de Pavlov eram a "nova ferramenta da psicologia" (Leahey, 1980). Watson ampliou o paradigma de condicionamento de Pavlov pareando um estímulo neutro com um estímulo eliciador de medo e, depois de vários pareamentos, o estímulo neutro eliciou a resposta de medo. Watson conseguiu condicionar o medo na criança em estudo. O pequeno Albert, de nove meses, desenvolveu medo de ratos brancos e posteriormente desenvolveu respostas generalizadas de medo em outros animais e outros objetos.

Mary Cover Jones, aluna de pós graduação de Watson, interessou-se em investigar como seria possível trabalhar experimentalmente para eliminar os medos condicionados. Ela realizou um estudo com 70 crianças e utilizou sete métodos de remoção de respostas de medo: eliminação por desuso, apelo verbal, repressão, adaptação negativa, distração, condicionamento direto e imitação social. O método de eliminação por desuso pressupunha que os medos desapareceriam gradualmente caso fossem apenas deixados de lado. O apelo verbal incluía persuasão e falar positivamente a respeito do estímulo temido. O método de repressão usava a provocação verbal feita por outras pessoas para tentar remover o medo. A adaptação negativa assemelhava-se a uma técnica de habituação em que o estímulo temido era repetidamente apresentado. O método de distração tentava desviar a atenção da criança para algo que não o estímulo temido. O condicionamento direto apresentava gradualmente o objeto temido, enquanto que o sujeito se engajava em uma atividade que eliciasse uma resposta agradável. Finalmente, o método da imitação social usava modelos de interações desejadas com o estímulo eliciador de medo e de reações a ele. As pesquisas de Jones evidenciaram a 
imitação social e o condicionamento direto como métodos bem sucedidos experimentalmente para o trabalho de remoção do medo (Jones, 1924).

As implicações das descobertas de Jones sobre a eliminação de medos em crianças tiveram impactos relevantes no campo da psicologia e no tratamento das fobias. A técnica de condicionamento direto de Jones é considerada a precursora da técnica conhecida como Dessensibilização Sistemática (Kalish, 1981).

No final dos anos 40, Joseph Wolpe, um psiquiatra sul-africano, desenvolveu o princípio da inibição recíproca ainda utilizando os princípios descritos por Pavlov de condicionamento clássico e do condicionamento contíguo de Edwin Guthrie. Nos anos 50, introduziu a Dessensibilização Sistemática, uma forma de tratamento que consistia inicialmente na exposição do indivíduo a um estímulo descrito pelo mesmo como eliciador de ansiedade e em seguida associá-lo a um estado de relaxamento. A exposição de Wolpe foi, a princípio, feita in vivo, mas posteriormente optou por fazê-la através do uso da imaginação:

"Comecei a organizar programas de exposição a estímulos fóbicos graduados ao vivo para pacientes que tinham adquirido alguma facilidade em relaxar, geralmente depois de 6 a 10 sessões. Mas esses programas eram muitas vezes difíceis de executar e comecei, portanto, a explorar a possibilidade de fazer uso de situações imaginárias, no lugar das reais". (Wolpe, 1973)

A década de 1930 é marcada pelo desenvolvimento do modelo behaviorista do americano Burrhus Frederic Skinner, onde ele elucida 0 ambiente como determinante do comportamento. Ele ainda se opõe às questões cognitivas que estavam surgindo na época, principalmente a partir das publicações dos estudos de Tolman sobre as variáveis intervenientes (1938).

Skinner desenvolveu um novo paradigma, o operante, por acreditar que grande parte do repertório comportamental humano não poderia ser explicado apenas pelo paradigma pavloviano (Costa, 2002). Para este autor, as consequências produzidas pelo comportamento atuam aumentando ou não a 
probabilidade deste ocorrer novamente. Iniciou seus estudos em pesquisas conceituais e históricas, além das pesquisas experimentais em laboratórios.

Skinner, após longos estudos, nomeou sua versão de "Behaviorismo Radical" e esta seria a filosofia por trás da ciência do comportamento que tentava tão fortemente implantar. Esta metodologia de ciência é conhecida como Análise Experimental do Comportamento.

Assim, a Análise do Comportamento que, vale lembrar, não se restringe à análise Experimental do Comportamento, origina-se, então, de uma nova posição behaviorista assumida por Skinner; parte da constatação é de que há lógica, ordem e regularidade nos comportamentos (Todorov, 2004) e portanto, merecem ser estudados.

A Análise do Comportamento tem como objeto de estudo as interações organismo - ambiente. Conforme propõe Skinner (1978), "As variáveis externas, das quais o comportamento é função, dão margem ao que pode ser chamado de análise causal ou fundamental. Tentamos prever e controlar o comportamento de um organismo individual. Esta é a nossa "variável dependente" - o efeito para o qual procuramos a causa. Nossas "variáveis independentes" - as causas do comportamento - são as leis de uma ciência" (p. 45). Desta forma, o material analisado provém de muitas fontes, entre elas da Análise Experimental do Comportamento.

O início dos anos 70 caracterizou um amplo questionamento sobre as práticas comportamentais. As terapias cognitivas ganharam força neste período, principalmente com as publicações dos estudos de Albert Ellis e Aaron Beck. Para os cognitivistas, as cognições distorcidas ou crenças irracionais poderiam ser reformuladas para diminuírem o impacto destas no funcionamento do indivíduo (Costa, 2002).

Nos anos 80 e 90, observa-se a integração dos dois modelos, é a chamada Terapia Cognitivo-Comportamental, que se torna uma grande referência em publicações sobre o tratamento da ansiedade e das fobias. Este modelo passa a ser mundialmente conhecido por suas inúmeras evidências clínicas (Barlow e Cerny, 1988; Beck et al., 1985; Clark e Beck, 1988). 
A Terapia Cognitivo-Comportamental busca auxiliar os pacientes alterando os aspectos cognitivos e comportamentais das respostas (Craske, 1999; Craske e Barlow, 1993). Este modelo apresenta alguns componentes estruturais, tais como: a) psicoeducação sobre o que é ansiedade e suas características, b) automonitoramento dos sintomas, c) relaxamento ou exercícios de respiração, d) reestruturação cognitiva, e) exposição ao vivo e na imaginação das imagens temidas, sensações corporais e situações (Arch e Craske, 2008).

As aplicações do conceito operante de Skinner foram descritas por ele até a década de 60. Em 1957, Skinner apresentou suas principais contribuições para o estudo mais aprofundado de um dos aspectos do comportamento humano que será, mais tarde, responsável pelo surgimento de uma nova onda de práticas psicoterápicas: o comportamento verbal.

A publicação de Verbal Behavior (1957) de Skinner trouxe grandes contribuições para o entendimento do comportamento verbal, principalmente sobre o efeito das regras e do controle verbal como determinantes do comportamento. Para os analistas do comportamento, a linguagem dá origem às práticas culturais que, além de organizar o funcionamento do grupo e suas estratégias para o manejo do ambiente físico, estabelecem também as normas para a interação entre os indivíduos (Andery, 1997).

Nos anos 1990, pesquisadores e clínicos passam a se interessar pelas terapias baseadas em Mindfulness e aceitação. A curiosidade e grande expectativa que estavam surgindo com estas novas propostas terapêuticas estavam ao mesmo tempo sendo acompanhadas por uma série de experimentos e pesquisas clínicas (Eifert e Forsyth, 2005; Twohig et al., 2006; Hayes et al., 2004). As chamadas terapias comportamentais da "terceira onda" despontaram nesta década e trouxeram novas formas de condução terapêutica e de manejo de sintomas.

As terapias mais conhecidas que buscaram integrar este conhecimento foram: A Terapia de Aceitação e Compromisso (Hayes, Strosahl e Wilson, 1999); a Terapia Analítico Funcional (Kohlenberg e Tsai, 1999); Terapia de Redução de Estresse e Mindfulness (Kabatt-Zinn, 1990); Terapia 
Comportamental Dialética (Linehan, 1993), e a Terapia da Auto-Compaixão (Gilbert, 2005).

\section{Terapia de Aceitação e Compromisso}

Neste cenário, a Terapia de Aceitação e Compromisso, aliada ao desenvolvimento do tema Comportamento Verbal, apresentou uma filosofia clínica especificamente elaborada para o manejo do sofrimento humano. Entende-se por sofrimento (psicológico) uma experiência reservada aos seres humanos, uma vez que, descrever e analisar a experiência vivida, olhar para a sua própria história ou mesmo antecipar o futuro, pode ser uma experiência considerada eminentemente verbal (Wilson e Soriano, 2002).

A Terapia de Aceitação e Compromisso fundamenta-se no Behaviorismo Radical e na Teoria dos Quadros Relacionais (Hayes et al., 1999). Esta teoria é uma extensão dos estudos de Sidman sobre equivalência de estímulos. Nesta perspectiva, eles ressaltam como a linguagem interfere nas cognições, emoções e no comportamento do indivíduo. A grande questão da linguagem e das cognições é que elas são aprendidas contextualmente e relacionadas de forma arbitrária (Hayes et al., 2001).

A Teoria dos Quadros Relacionais considera, não apenas as relações de equivalência, denominadas por Hayes e colaboradores de coordenação, mas também outros tipos de relações treinadas pela comunidade verbal por meio de diversas situações durante a vida, como relações de oposição, distinção, comparação, hierarquia, temporalidade, espacialidade, condicionalidade e causalidade e relações deíticas (localização no tempo e espaço) (Hayes et al., 2001). Esta capacidade de relacionar estímulos, segundo este modelo, amplifica a estimulação aversiva vivenciada na história de vida nas relações construídas por meio da linguagem e propicia um repertório de fuga e esquiva. A Terapia de Aceitação e Compromisso busca diminuir esse repertório de fuga e esquiva, e busca motivar e treinar outras respostas alternativas reforçadas positivamente. 
A Terapia de Aceitação e Compromisso também integra os conceitos de mindfulness e aceitação para favorecer a flexibilidade psicológica e promover mudança comportamental baseada nos valores do cliente. O termo flexibilidade psicológica é definido como o aumento da capacidade do cliente em permanecer em contato com o momento presente, escolhendo ações consistentes com os seus valores pessoais (Hayes et al, 1999).

O indivíduo que procura atendimento psicoterapêutico está, em geral, utilizando seu repertório de tentar evitar os eventos privados internos aversivos sem sucesso. Como o indivíduo está com foco na redução de seus sintomas, ele geralmente está engajado na procura de situações ou ações que geram alívio em curto prazo. Com o tempo, o repertório comportamental deste indivíduo encontra-se limitado (Hayes et al., 1999). Além disso, quanto mais o indivíduo estiver engajado nos comportamentos de esquiva, menos ele estará se comportando para obter situações de satisfação e prazer em sua vida.

Neste sentido, a Terapia de Aceitação e Compromisso dá alicerces para que a pessoa pare de controlar e evitar as emoções, sensações e pensamentos desagradáveis. Assim, o objetivo deste modelo não é abrandar tais emoções e sensações e sim aumentar a tolerância sobre esses eventos (Hayes et al., 1999).

Assim, segundo esta teoria, perde-se contato com valores pessoais quando o paciente fica emaranhado numa luta consigo mesmo através de seus pensamentos, verbalizações, regras, catastrofização e emoções. $O$ objetivo deste modelo seria, portanto, o afastamento do conteúdo da linguagem através do uso da desfusão (em tradução para defusion) e da prática da aceitação para a administração dos conteúdos emocionais (Hayes e Duckworth, 2006).

O uso da desfusão diminui o impacto negativo dos pensamentos do cliente, principalmente ensinando sobre como se distanciar deles. Além disso, terapeutas encorajam seus clientes a tratarem seus pensamentos como apenas pensamentos, ao contrário de levá-los ao pé da letra (Healy et al., 2008). 
No tratamento da ansiedade e das fobias, além da desfusão, protocolos da Terapia de Aceitação e Compromisso envolvem o uso da desesperança criativa, o trabalho com valores pessoais, e ações com compromisso. A desesperança criativa ajuda o cliente na compreensão de que suas tentativas de mudança ou controle da ansiedade não foram bem sucedidas e que contribuíram para uma limitação de seu repertório comportamental. Os trabalhos com os valores ajudam o cliente a elucidar quais os aspectos de sua vida são realmente importantes e o quanto ele está comprometido, realizando as ações consistentemente de acordo com eles.

A aceitação é ensinada neste modelo como uma alternativa para evitar a esquiva experiencial. A esquiva experiencial pode ser entendida como a tentativa de luta ou controle dos próprios eventos privados. Já a aceitação envolve estar consciente de tais eventos (os privados) sem que haja tentativas desnecessárias de mudar sua frequência ou forma. Por exemplo, pacientes com ansiedade são ensinados a sentir ansiedade integralmente e sem defesa (Hayes et al., 2004).

Além disso, encoraja-se o cliente a vivenciar todas as suas emoções e pensamentos de forma aberta, evitando ao máximo os julgamentos sobre eles. A prática do Mindfulness é encorajada neste momento, a partir da observação do momento presente e das manifestações que estão ocorrendo no indivíduo (emoções, pensamentos, memórias, etc.) sem crítica. Esta prática auxilia ainda na discriminação desses eventos, uma vez que o cliente muitas vezes tem dificuldade de descrever e nomear as emoções sentidas.

Os tratamentos para ansiedade e fobias baseados na Terapia de Aceitação e Compromisso (Kashdan et al., 2013; Zettle, 2003; Forman et al., 2012; Roemer et al., 2008, Brown et al., 2011) também esclarecem a exposição como procedimento terapêutico. No entanto, o objetivo da exposição neste modelo é diferente dos modelos comportamentais cognitivos. O objetivo não é a extinção ou diminuição do medo e sim contribuir para que o cliente aprenda novos repertórios para lidar com a ansiedade de forma flexível (aceitação) e contribuir para a diminuição das respostas de esquiva (Eifert e Forsyth, 2005). 
A maioria dos tratamentos para ansiedade tem como objetivo específico a redução da ansiedade e dos estímulos fóbicos. A Terapia de Aceitação e Compromisso têm como proposta uma ênfase diferente desta, que é uma mudança na forma como a pessoa se relaciona com a ansiedade. $O$ mesmo raciocínio é utilizado para emoções em geral, sensações físicas, memórias e outras formas de eventos privados (Segal et al., 2004).

Assim, diferente de outras abordagens, este modelo ajuda o indivíduo no exercício do aprender a manejar suas emoções de uma forma mais aberta, sem tentativas de controle e diminuição destas. Para isso, muitas vezes recorre-se ao uso de metáforas que podem ser apresentadas na forma de histórias ou outros recursos como letras de músicas, histórias em quadrinhos ou qualquer outro meio que favoreça a instrução de comportamentos mais eficazes. Assim, comportamentos governados por regras antigas e ineficazes são reavaliados e novas regras apresentadas. Além disso, as metáforas auxiliam os clientes na descrição de possíveis consequências de seus comportamentos, ou seja, promovem um olhar direto para as contingências que estão operando no momento (Hayes et al., 1989).

Um dos problemas da exposição no tratamento das fobias é ela ser um procedimento de caráter aversivo (Hayes et al., 1990). O paciente é convidado a vivenciar o medo através de procedimentos que o encorajam a se aproximar deste (no caso, o de espaços fechados) e não evitá-lo. Para a Terapia de Aceitação e Compromisso, evitar ou fugir do medo seria o que mantém o problema do paciente. Esta evitação ou fuga da experiência do medo é chamada, neste modelo, de esquiva experiencial.

Para sintetizar, A Terapia de Aceitação e Compromisso tem como objetivo principal: a aceitação de pensamentos, sentimentos, sensações corporais e memórias aversivas, ou seja, a diminuição de comportamentos de fuga e esquiva de tais eventos e o engajamento em ações que produzam reforçamento positivo (Hayes et al., 1999). Todas essas etapas são desenvolvidas com o foco no que está acontecendo no momento presente (mindfulness). 
Este modelo tem se mostrado promissor no tratamento de uma série de transtornos mentais como é o caso da ansiedade, depressão, abuso de substâncias e dor crônica (Hayes et al., 2006). Ensaios clínicos randomizados têm mostrado que a Terapia de Aceitação e Compromisso foi efetiva no tratamento do Transtorno de Pânico (Eifert e Heffner, 2003; Levitt et al, 2001).

Evidências apontam a Terapia Cognitivo-Comportamental como modelo terapêutico que apresenta um número de estudos e publicações consistentes e empiricamente constituídos (Ost, 2008). No entanto, estudos sobre as terapias comportamentais da terceira geração (Gregg et al., 2007; Gratz e Gunderson, 2006; Lundgren et al., 2006; Woods et al., 2006; Gaudiano e Hebert, 2006) ainda apresentam problemas metodológicos (Ost, 2008) como número reduzido de sujeitos nas amostras, ausência de comparação com outros modelos terapêuticos e uso de instrumentos de avaliação não compatíveis com o transtorno em questão. Estes problemas suscitam a importância de novos estudos na área com critérios e desenvolvimentos mais adequados para um tratamento empiricamente comprovado.

Além disso, a preocupação com as evidências empíricas dos atendimentos psicológicos vêm crescendo, o que pode ser decorrente das pressões econômicas, políticas e legais derivadas da crescente atenção aos direitos dos consumidores nas últimas décadas. Este fator tem influenciado a comunidade psicológica clínica internacional na busca de demonstrações empíricas da qualidade dos serviços que oferecem (Starling, 2010).

\subsection{Justificativa}

Há necessidade de desenvolver tratamentos alternativos ao atual uso de sedação para o tratamento da fobia de espaços fechados, em especial das pessoas com medo de realizar o exame de ressonância magnética. Estes precisam ser breves e práticos por conta de o paciente estar com o exame agendado ou ter urgência do diagnóstico e do início imediato de um possível tratamento. A Terapia de Aceitação e Compromisso, por seu bom resultado no tratamento de outros transtornos de ansiedade, pode ser uma opção de tratamento. 


\subsection{Objetivo}

Verificar se uma sessão de Terapia de Aceitação e Compromisso é tão eficaz quanto sete sessões deste mesmo modelo terapêutico para o tratamento de pacientes com fobia de espaços fechados ou de realizar Ressonância Magnética.

\subsection{Hipóteses}

Uma sessão de Terapia de Aceitação e Compromisso será tão eficaz quanto sete sessões do mesmo modelo terapêutico. 


\section{Método}

\subsection{Amostra}

A amostra deste estudo foi composta por 30 pessoas de ambos os gêneros e que se inscreveram para participar das sessões de tratamento para fobia de espaços fechados. Participaram indivíduos que atenderam aos seguintes critérios: idade igual ou maior do que 18 anos ou igual ou menor do que 60 anos, apresentar diagnóstico de fobia de espaços fechados ou recusa em realizar exame de Ressonância Magnética, demonstrar capacidade cognitiva para responder às questões dos instrumentos de coleta de dados, disponibilidade para frequentar de um a sete atendimentos e concordar em participar do estudo, assinando o Termo de Consentimento Livre e Esclarecido. (Anexo 1)

Foram excluídos da amostra os pacientes que apresentavam risco iminente de suicídio, tendência à automutilação, psicose não estabilizada e pacientes com algum risco clínico que inviabilizasse os atendimentos.

O cálculo do tamanho da amostra foi baseado na literatura em que cerca de $2 \%$ dos pacientes precisariam de anestesia para a realização do exame, e foi feita por meio de uma simulação de regressão logística que sugeriu o número de 30 pacientes.

\subsection{Local}

O estudo foi realizado em um hospital público na cidade de São Paulo.

2.3 Instrumentos 
A coleta de dados foi realizada por meio de quatro instrumentos: um questionário biossociodemográfico, Questionário de Claustrofobia, Inventário de Depressão de Beck e Inventário de Ansiedade (IDATE Estado). Os instrumentos foram aplicados antes do início da primeira sessão, na última sessão de ambos os tratamentos e após três meses do término do tratamento.

\subsubsection{Questionário Biossociodemográfico (anexo 2)}

Um questionário para a coleta dos dados biossociodemográficos foi criado para obtenção dos dados dos participantes. O formulário continha as seguintes variáveis sociodemográficas: nome, número de registro no sistema do hospital, gênero, idade, estado civil, escolaridade, profissão, situação empregatícia, nacionalidade e naturalidade. O questionário também apresentava variáveis clínicas como: descrição de doenças prévias, descrição de histórico psiquiátrico, medicamentos psiquiátricos em uso, histórico anterior com exames de Ressonância Magnética e desfecho, histórico anterior em situações de espaços fechados, histórico familiar de transtorno mental ou fobia de espaços fechados. Para o diagnóstico preciso de fobia de espaços fechados, utilizou-se o diagnóstico operacional segundo o DSM IV - TR (APA, 2002) abrangendo todos os critérios de A a G.

Neste questionário também constavam perguntas sobre possíveis tentativas de suicídio, psicose e automutilação.

\subsubsection{Questionário de Claustrofobia (ANEXO 3)}

Para mensurar os sintomas de fobia de espaços fechados, utilizou-se o instrumento "Questionário de Claustrofobia" de Rachman e Taylor (1993) em razão de sua ampla utilização em pesquisas relacionadas ao tema e por 
ser um instrumento de fácil preenchimento. A versão que será utilizada para este estudo foi composta de 26 itens cuja adequação psicométrica foi comprovada por Radomsky et al. (2001). O instrumento foi testado e validado em população brasileira por Silva (2013).

Este instrumento consta de questões que envolvem exemplos de situações de confinamento e asfixia. As respostas são do tipo Likert, variando de 1 a 4 , sendo que atribuir 1 significa que o exemplo deixa 0 participante nada ansioso, atribuir 2 indica levemente ansioso, atribuir 3 indica muito ansioso e 4 indica extremamente ansioso. A interpretação dos dados se dá a partir da soma dos números assinalados pelo participante.

\subsubsection{Inventário de Depressão de Beck}

Para mensurar possíveis sintomas de Depressão dos participantes, utilizou-se o "Inventário de Depressão de Beck" (Beck et al., 1961), que é provavelmente a medida de autoavaliação de depressão mais utilizada tanto em pesquisa como em clínica (Dunn et al., 1993). Ele consiste em 21 itens, incluindo sintomas e atitudes, cuja intensidade varia de 0 a 3 . Os itens referem-se à tristeza, pessimismo, sensação de fracasso, falta de satisfação, sensação de culpa, sensação de punição, autodepreciação, autoacusações, idéias suicidas, crises de choro, irritabilidade, entre outros. Ele foi traduzido para vários idiomas e validado em diversos países. Aqui no Brasil, a versão em português foi validada por Gorestein e Andrade (1996). As folhas de respostas utilizadas foram da versão BDI-lie e foram adquiridas na Casa do Psicólogo.

2.3.4 Inventário de Ansiedade Traço-Estado IDATE (ANEXO 4) 
O Inventário de Ansiedade Traço-Estado (IDATE) foi criado por Spielberger, Gorsuch e Lushene (1970). Foi traduzido e validado para o português falado no Brasil por Biaggio e Natalicio (1979). O Inventário apresenta duas escalas e foi escolhido por ser atualmente um instrumento bastante utilizado em pesquisas que envolvem ansiedade e por ser de fácil preenchimento. As folhas de respostas do inventário foram adquiridas para uso no Centro de Psicologia CEPA.

As escalas de ansiedade de estado e traço apresentam 20 questões cada e as respostas são do tipo Likert, variando de 1 a 4 , ou seja, $1=$ absolutamente não, 2 = um pouco, 3 = bastante e $4=$ muitíssimo. A interpretação dos dados se dá a partir da soma dos números assinalados pelo participante.

\subsection{Procedimento}

Realizou-se um ensaio clínico randomizado, com dois grupos paralelos. Os trinta pacientes com fobia de espaços fechados foram aleatoriamente divididos em dois grupos de quinze pacientes em cada grupo. Quinze pacientes (grupo A) foram tratados com uma sessão de Terapia de Aceitação e Compromisso e os outros quinze pacientes (grupo B) foram tratados com sete sessões do mesmo modelo terapêutico. A duração do tratamento do grupo $A$ foi de 65 minutos por participante e no grupo $B$ foram feitas sete sessões de quarenta minutos de duração cada.

A coleta de dados foi iniciada em Fevereiro de 2012 e finalizada em Setembro de 2013. Primeiramente foram contatados os responsáveis pelo setor de Ressonância Magnética do Instituto de Psiquiatria do Hospital das Clínicas da Faculdade de Medicina da Universidade de São Paulo e do Instituto de Medicina Nuclear do Hospital para um possível encaminhamento de pacientes. Como o número de encaminhamentos não foi suficiente, iniciou-se divulgação do projeto na mídia. Para isso, recorreuse ao serviço de assessoria de imprensa do hospital, que divulgou o projeto em meios de comunicação como rádio, jornal e no site da Universidade de 
São Paulo. A divulgação apresentou as características do transtorno e suas implicações para os exames de Ressonância Magnética e solicitou que possíveis participantes entrassem em contato com a pesquisadora executante através de um endereço de e-mail. Vinte e nove dos trinta participantes foram recrutados por este meio e um participante foi encaminhado internamente pela equipe do hospital.

A partir do e-mail manifestando o interesse em participar da pesquisa, cada participante foi contatado para levantamento de um breve histórico, como idade e história anterior com ressonância magnética ou fobia de espaços fechados. Caso o participante apresentasse idade entre 18 e 60 anos e exemplos de recusa de realização de exame ou fobia de espaços fechados, uma consulta de triagem foi então agendada com o médico psiquiatra colaborador da pesquisa, para assegurar a presença de dois possíveis diagnósticos: 1) recusa de realizar ressonância magnética ou 2) fobia de espaços fechados. Para os participantes com diagnóstico de fobia de espaços fechados, procuraram-se evidências sobre experiência prévia com exames de Ressonância Magnética e desfecho.

Nesta consulta de triagem, caso o participante apresentasse todos os critérios de inclusão necessários, o médico descreveria a pesquisa, frequências necessárias, horários de atendimento e solicitaria ao participante que preenchesse $\circ$ Termo de Consentimento Livre e Esclarecido.

Com a inclusão do participante na pesquisa, este era encaminhado para o procedimento de randomização. Para isso, solicitou-se a uma pessoa independente do estudo realizar a divisão dos pacientes em grupo $\mathrm{A}$ e grupo B. Esta pessoa foi a secretária da clínica da pesquisadora executante. Para a divisão dos grupos, utilizou-se uma tabela de números aleatórios no ncontrada site HTTP://www.fpce.uc.pt/niips/spss prc/0 organ/tabela na/tabela.htm

(ANEXO 5). Utilizaram-se números de 1 a 30, e cada número aleatório foi organizado em uma folha de randomização (ANEXO 6), e ao lado de cada número foi adicionada a letra $\mathrm{A}$ ou $\mathrm{B}$. Cada participante era incluído na 
tabela assim que era aprovado na triagem, e após ter assinado o Termo de Consentimento. Assim, o primeiro participante apto para a pesquisa foi considerado o número 1 da planilha e seu grupo atendimento seria apresentado com a letra $A$ para 1 sessão e com a letra $B$ para 7 sessões. $E$ assim sucessivamente.

De posse da informação da randomização, a pesquisadora executante entrou em contato com o participante via e-mail para o agendamento da primeira sessão de atendimento. Na data dos atendimentos, os pacientes eram solicitados a aguardar em local diferente da sala de atendimento, para evitar o encontro de participantes de grupos diferentes. Além disso, os agendamentos eram feitos de duas em duas horas, também para evitar esses encontros.

As sessões foram realizadas às terças feiras, no período da manhã, na própria sala do simulador de ressonância magnética do instituto. Nesta primeira sessão, a pesquisadora informava sobre o número de sessões, apresentava informações sobre a Terapia de Aceitação e Compromisso e esclarecia outras dúvidas sobre a pesquisa. Após esta introdução, a aplicação dos instrumentos de coleta de dados foi feita. Para isso, a pesquisadora apresentou cada um dos questionários, realizando a leitura da primeira pergunta, e explicando como responder as alternativas do tipo Likert. Após a certificação do entendimento do participante, o preenchimento era feito pelo próprio, até sua finalização. Os participantes preencheram cada instrumento em folha de papel e caneta. Não houve acompanhantes no momento de coleta de dados. Após três meses de tratamento, os pacientes foram novamente convocados para a reaplicação dos instrumentos mencionados.

Após finalização do preenchimento dos instrumentos, a primeira sessão era iniciada. Nas sessões do grupo A e B, a pesquisadora explicou ao participante que ele aprenderá estratégias para lidar com a fobia de espaços fechados. Ela então perguntou ao participante quais são os pensamentos e sensações que ocorreram durante a realização do exame de Ressonância Magnética anterior. Para o participante que não realizou o 
exame, a pesquisadora perguntou sobre quais sensações e possíveis pensamentos poderiam ser vivenciados durante o exame.

A pesquisadora então explicou que o participante aprenderá a fazer algo diferente com tais sensações e pensamentos vivenciados de modo que este tenha uma nova performance na realização de um novo exame.

Para os participantes do grupo $A$, ao final da primeira sessão foi realizado $O$ agendamento da sessão de exposição no simulador. A pesquisadora explicou cuidadosamente para o participante sobre esta etapa, uma vez que muitos deles comentaram nervosismo com a sessão. Para os participantes do grupo $\mathrm{B}$, a sessão de exposição no simulador foi agendada após a sétima sessão. $O$ simulador de ressonância magnética utilizado neste estudo foi construído em função de um projeto de pesquisa "Estudo Psicobiológico da Regulação Emocional a partir dos Efeitos de Antidepressivos" (Projeto Temático FAPESP №. 01/00189-9). Este simulador de Ressonância Magnética é uma réplica do aparelho convencional, mas sem a presença do magneto. Ele possui campo fechado e a movimentação da maca é feita de forma mecânica. Para simular o ruído do aparelho, uma caixa de som emite uma gravação e fica em um local não visível ao paciente. $O$ teto do túnel é bastante próximo ao rosto do paciente e os braços geralmente tocam nas laterais do aparelho.

\section{Descrição do tratamento}

A opção por sete sessões de Terapia de Aceitação e Compromisso engloba todos os sete princípios deste modelo terapêutico, a saber: "Desesperança Criativa", "Aceitação", "Desfusão", "Eu como Contexto", "Momento presente", "Valores" e "Ações com Compromisso". Já na sessão breve (uma única sessão) será trabalhado cada um dos princípios da ACT de forma resumida. O protocolo de uma sessão e de sete sessões utilizado neste estudo foi de Páez-Blarrina, Luciano, Gutiérrez-Martinez, Valdivia, Ortega, Rodríguez-Valverde (2008). 
A qualidade do tratamento oferecido foi analisada a partir da gravação de uma sessão de cada um dos grupos e avaliada por um terapeuta independente do estudo, experiente no modelo da Terapia de Aceitação e Compromisso.

Grupo A - Uma sessão

Esta sessão consistiu de três fases: introdução, metáfora sobre desfusão e aceitação, metáfora sobre valores. A sessão A teve duração de 65 minutos, em média.

A) Introdução

A pesquisadora explicou os objetivos do estudo e suas implicações clínicas, que é ajudar pessoas que sofrem com a fobia de espaços fechados. Ela disse: "Como você sabe, muitas pessoas têm medo de espaços fechados, mas eles persistem em suas atividades mesmo com algum desconforto. Este experimento é sobre isso. Sabemos que você poderá sentir algum desconforto durante a realização do exame de ressonância magnética, mas precisamos saber como você lida com este desconforto". Esta fase tem duração de cinco minutos.

B) Metáfora sobre desfusão e aceitação (Hayes, Strosahl e Wilson, 1999 p. 162)

O participante foi solicitado a relatar três pensamentos associados à realização do exame de Ressonância Magnética, por exemplo, "não há ar suficiente dentro do aparelho".

Cada um dos pensamentos é escrito em um papel e dobrado de modo que o participante não consiga ler o conteúdo. A pesquisadora então 
escolhe um dos papéis e pergunta: "Imagine que este papel contém um de seus pensamentos. Agora, levante-se e veja se você consegue fazer coisas nesta sala mesmo levando este papel em seu bolso, algo como andar ou exercitar-se, por exemplo." Após a realização da tarefa, o participante é convidado a sentar novamente e é solicitado que leia o papel que estava em seu bolso. Após a leitura, a pesquisadora explicou sobre a possibilidade de realizar as atividades do dia a dia mesmo com tais pensamentos presentes. Como exemplo, o experimentador solicita que o participante leia o papel que estava em seu bolso. Após a leitura do pensamento a pesquisadora pergunta: "Você conseguiria permanecer realizando o exame de ressonância magnética mesmo pensando que não há ar suficiente dentro do aparelho"? Esta fase tem duração de trinta minutos.

C) Metáfora sobre valores

O objetivo desta etapa foi favorecer que o participante faça relação entre eventos privados e ações rumo aos valores. Para isso, a pesquisadora diz: "Você já ouviu ou conhece alguém que foi submetido à quimioterapia? Você sabe que em alguns momentos este tratamento é bastante aversivo, as pessoas relatam sentir enjoo e tonturas, eles perdem cabelo e sentem uma série de sintomas desconfortáveis. Mas, mesmo com todas essas implicações, poucas pessoas se recusam a realizar quimioterapia. Você saberia dizer por que as pessoas não se recusam a realizar este procedimento?" O participante pode responder algo do tipo: "Porque a pessoa precisa deste tratamento para ser curado". A pesquisadora continuou dizendo: "Exatamente, porque sentir este desconforto pode significar a cura para o câncer no longo prazo e até mesmo melhorar a qualidade de vida do paciente". "Você já esteve, não nesta situação específica, mas em alguma situação similar onde você sentiu algum desconforto por um período de tempo de modo a alcançar algo valioso na sua vida"? A pesquisadora então solicitou que o participante dê dois ou três exemplos que correspondem a estas experiências. Se o participante não responder, a pesquisadora ofereceu outro exemplo: "Por exemplo, quando 
você visita o dentista, naquele exato momento é doloroso e incômodo, mas você faz isso porque precisa ter uma boca saudável". Imediatamente após este segundo exemplo, é solicitado um terceiro para o participante.

Após esta etapa, o experimentador disse: "O objetivo deste estudo é ajudar pessoas a realizarem o exame de ressonância magnética ao mesmo tempo em que a pessoa vivenciará muito desconforto e pensamentos desagradáveis. Assim, durante a realização do procedimento, tenha em mente que o tempo que você permanecerá dentro do aparelho será muito importante para a sua saúde. Pense que estes minutos desconfortáveis podem ser fundamentais para o seu futuro, de modo que saberemos muitas informações sobre algo muito valioso: sua saúde." Esta etapa teve duração de trinta minutos.

\section{Grupo B - Sete Sessões}

Cada uma das sete etapas da Terapia de Aceitação e Compromisso foram trabalhadas: Desesperança criativa, Desfusão, Aceitação, Eu como contexto, Momento presente, valores e ações compromissadas.

Primeira sessão: Trabalho com a chamada Desesperança Criativa: determinação dos hábitos e comportamentos para esquiva de locais fechados e quais tentativas de resolução foram utilizadas. Esta sessão consistiu de três etapas: Introdução, metáfora sobre Desesperança Criativa (Hayes et al., 1990) e conclusão.

A) Introdução

A pesquisadora explicou os objetivos do estudo e suas implicações clínicas, que é ajudar pessoas que sofrem com a fobia de espaços fechados. Ela disse: "Como você sabe, muitas pessoas têm medo de espaços fechados, mas eles persistem em suas atividades mesmo com algum desconforto. Este 
experimento é sobre isso. Sabemos que você poderá sentir algum desconforto durante a realização do exame de ressonância magnética, mas precisamos saber como você lida com este desconforto". Esta etapa teve duração de cinco minutos.

B) Trabalho sobre a Desesperança Criativa. Utilização da metáfora do "Homem no Buraco" (Hayes et al., 1999, p. 101).

A pesquisadora iniciou com a seguinte fala: "Agora vamos juntos identificar as estratégias que você encontrou para permanecer em espaços fechados. Estas estratégias costumam ser efetivas em curto prazo; normalmente o indivíduo tenta parar de pensar que pode sufocar-se ou tenta distrair-se, por exemplo. As pessoas conseguem algum sucesso num primeiro momento, mas o pensamento tende a voltar, tornando estas estratégias ineficazes em longo prazo e gerando a necessidade de mais controle, resultando em mais limitações na vida da pessoa".

Para identificar as estratégias sem sucesso utilizadas pelo participante, a pesquisadora apresentou o seguinte texto: "A situação em que você está se parece um pouco com isto. Imagine que você está num campo, usando uma venda e lhe foi dada uma pequena mala de ferramentas para carregar. Disseram-Ihe que a sua tarefa era correr por este campo sem enxergar nada. Então você faz o que Ihe disseram. Mas, sem que você saiba, há vários espaços neste campo, ou seja, buracos muito profundos. A princípio você não sabe disso. Então você começa a correr e mais cedo ou mais tarde você cai num grande buraco. Você analisará este novo ambiente e verifica que não há como escalá-lo, nem rotas alternativas. Provavelmente o que você faria em tal situação é pegar uma mala de ferramentas e ver o que tem dentro dela; talvez tenha algo que você possa usar para sair do buraco. Suponha que a única ferramenta da mala seja uma pá. Então você começa a cavar, mas rapidamente descobre que não está caminhando para sair do buraco. Então você tenta cavar cada vez mais. Mas você ainda está no buraco. Então você tenta dar grandes cavadas, ou pequenas, ou jogar a terra para longe. Mas 
mesmo assim você continua no buraco. Todo este esforço de trabalho e o buraco só aumentam. Não é esta a sua experiência? Talvez você tenha pensado: 'pode ser que nesta pesquisa eles tenham uma enorme pá, uma pá especial.' Bem, eu não tenho. E mesmo que eu tivesse, eu não usaria, porque cavar não é uma saída do buraco, cavar é o que faz buracos. Você não pode cavar a sua saída pois isto só aumenta o buraco".

Este texto pode ser lido pelo próprio participante ou, caso este prefira, a pesquisadora lê. Esta etapa tem duração de 30 minutos.

C) Conclusão

Após a leitura, a pesquisadora pediu exemplos sobre quais alternativas 0 participante tem utilizado para tentar resolver ou lidar com sua fobia de espaços fechados. Algumas alternativas podem ser: evitar situações ou locais fechados, tentativas de distração, tentativas de controle tais como medicação, drogas, entre outras. Depois de enumerados alguns exemplos, o experimentador perguntou sobre a eficácia de tais tentativas. $O$ objetivo foi identificar se tais estratégias trouxeram alívio imediato, mas que em longo prazo a fobia continua presente. As perguntas sobre a eficácia tiveram como finalidade confrontar o sistema de resolução de problemas do participante. 0 confronto não foi entre a pesquisadora e participante, mas sim entre o sistema de resolução de problemas e a própria experiência do participante. Nisto consiste a Desesperança Criativa: fazer o participante perder a esperança no antigo sistema de solução para que ele esteja aberto para uma nova proposta terapêutica. Esta etapa teve duração de cinco minutos.

Segunda sessão: Trabalho sobre aceitação. Esta sessão consistiu de duas etapas: Introdução e metáfora sobre aceitação (Hayes et al., 1990).

A) Introdução 
A pesquisadora iniciou a segunda sessão recapitulando a idéia introduzida na primeira sessão. Ela disse: "Imagine que você foi ao médico dizer que está com dor de cabeça e o médico olha e vê que você está batendo a cabeça para tentar parar com a dor. Você até pode saber que está batendo, mas você tem uma ótima justificativa para fazer isso: tentar se livrar da dor de cabeça. No entanto, a primeira coisa que o médico diz é que precisamos olhar para o seu braço, pois é lá que está o problema, e não na sua cabeça. E assim é como você tem feito com a ansiedade em espaços fechados: você pensa que está resolvendo tentando controlar ou evitar situações deste tipo, mas a solução está em outro lugar". Esta etapa teve duração de cinco minutos.

B) Metáfora sobre aceitação

A pesquisadora então disse que farão um exercício. Com papel e caneta na mão, ela desenhou uma escala parecida com os volumes de aparelhos de som. Ela então disse: "Veja que eu desenhei duas escalas aqui, e elas são parecidas com as escalas de volume de um aparelho de som. Uma das escalas chamada de ansiedade (ou medo de espaços fechados) e esta escala iniciará no 0 e irá até 10. A outra escala levará o nome de tolerância e também terá uma variação de 0 até 10 . Veja se o que está acontecendo com você é o seguinte: o que trouxe você aqui é que diante de situações onde os espaços são restritos ou muito fechados, a sua ansiedade fica alta. E assim, com esta ansiedade alta, você vem hoje participar desta pesquisa e tem como expectativa que eu lhe ajude a sentir menos ansiedade. No entanto, vou convidar você para olhar para esta outra escala, que chamamos de tolerância. Esta escala, na verdade, é a mais importante das duas pois é aquela que vai fazer a diferença. Quando a sua ansiedade diante de espaços fechados sobe para 10 e a sua escala de tolerância é 0, quer dizer que você provavelmente está tentando controlar esta ansiedade, ou mesmo fazer com que ela diminua, ou seja, você não está disposto a sentir tal ansiedade. É como se ao mesmo tempo que a sua ansiedade aumenta, a sua tolerância a ela diminui e tudo o que você tenta fazer é se livrar dela. Você provavelmente vem tentando controlar sua ansiedade há muito tempo e provavelmente sem sucesso. Assim, 
vou convidar você para fazer diferente: no lugar de olhar para esta escala (o experimentador aponta para a escala denominada ansiedade), vamos tentar olhar para a escala que chamamos de tolerância. Se nós passamos a olhar para esta escala ao invés de nos fixarmos na escala da ansiedade, você então estará deixando de dar importância para o controle da ansiedade. Você sairá deste ciclo vicioso no qual você entrou e que é pouco eficaz pois é o que você vem tentando há bastante tempo." Esta etapa teve duração de trinta minutos.

Terceira sessão: Trabalho com a chamada Desfusão. Esta sessão consistirá de duas etapas: introdução e metáfora sobre Desfusão (Hayes et al., 1999 p. 162).

A) Introdução

O participante foi solicitado a relatar três pensamentos relacionados à realização do exame de ressonância magnética, por exemplo: "não há ar suficiente dentro do aparelho" ou "vou ter um ataque de pânico". Cada um dos pensamentos foi escrito em um papel e dobrado de modo que o participante não pudesse ler o conteúdo. Esta etapa teve duração de cinco minutos.

B) Metáfora sobre Desfusão

A pesquisadora então escolheu um dos papéis e perguntou para 0 participante: "Imagine que este papel contém um de seus pensamentos. Agora, levante-se e veja se você consegue fazer coisas nesta sala mesmo levando este papel em seu bolso, algo como andar ou exercitar-se, por exemplo. "Após a realização da tarefa, a pesquisadora convidou o participante a sentar novamente e solicitou que ele lesse o papel que estava em seu bolso. Após a leitura do papel, ela explicou sobre a possibilidade de se realizar as atividades do dia a dia mesmo com tais pensamentos presentes. Como exemplo, a pesquisadora solicitou que o participante leia o papel que estava em seu bolso. Após a leitura do pensamento, ela perguntou: "Você conseguiria permanecer 
realizando o exame de ressonância magnética mesmo pensando que não há ar suficiente dentro do aparelho?". Esta etapa teve duração de trinta minutos.

Quarta sessão: Trabalhar com o conceito Eu como Contexto. Esta sessão teve duas etapas: introdução e metáfora sobre Eu como Contexto (Hayes et al., 1990).

A) Introdução

A pesquisadora disse que farão juntos outro exercício. Ela desenhou uma casa e alguns móveis dentro dela. Ela então disse: 'Imagine que você é esta casa, cheia desses móveis que a complementam. Estes móveis não são e nunca serão a casa. Os móveis são algumas partes de uma casa, ou o que há dentro dela. As casas apenas contêm alguns itens que farão da casa um lugar diferente para se morar. Mesmo que os móveis sejam bons ou ruins, eles pouco dizem sobre a casa. Assim, neste exemplo, é como se você fosse a casa, mas não os móveis. Seus pensamentos e suas emoções podem ser como os móveis de uma casa, eles são apenas complementos. Você não é os seus pensamentos e emoções. Você é você, e dentro de você existem complementos como pensamentos e emoções. Eles são apenas experiências que você tem. Esta fase teve duração de cinco minutos.

B) Metáfora Eu como Contexto

A pesquisadora disse que farão outro exercício. Ela pediu para 0 participante dar alguns exemplos de papéis que ele desempenhou na vida, como papel de professor (a), papel de filho (a), papel de síndico (a), etc. Quando o participante respondeu sobre os papéis desempenhados, ela então disse: "Imagine que um dos seus papéis é este (dar exemplo que o participante sugeriu). Você desempenha tal papel em algumas situações apenas, não é? 
Nós desempenhamos diversos papéis e eles também mudam a depender do dia, dos anos ou das situações. Você pode ter desempenhado um papel que hoje não desempenha mais (por exemplo: papel de estudante). Nós desempenhamos diferentes papéis até mesmo ao longo de um só dia. Eu agora estou desempenhando o papel de pesquisadora, mas daqui a pouco poderei desempenhar outro, o de passageiro de um ônibus, por exemplo. Perceba que estamos como observadores desta cena: ao sair desta sala com você eu serei um passageiro. Assim nós desempenhamos papéis, mas não somos esses papéis. A pesquisadora então pede outro exemplo para 0 participante. Esta etapa teve duração de 30 minutos.

Quinta sessão: Trabalhar com o momento presente. Esta sessão consistirá em uma etapa em que se utilizará um exercício de Mindfulness (Stahl e Goldstein, 2010).

\section{A) Exercício de Mindfulness}

Para a realização desta sessão, a pesquisadora explicou: "Nesta sessão, realizaremos um exercício que favorecerá o contato com o momento presente. Estamos acostumados a nos preocupar com o futuro ou remoer o passado, e são poucas as ocasiões em que estamos completamente no presente, o que é uma ironia uma vez que vivemos somente no presente. Para isso, faremos um exercício diferente hoje. Vou pedir para você se sentar de maneira confortável na sua cadeira e quando estiver pronto, convido você para fechar os olhos e acompanhar minhas instruções. Este exercício é muito simples. Vou pedir para que você leve sua atenção para a sua respiração. Permita que $o$ ar entre pelo nariz e percorra o caminho até chegar aos seus pulmões. Preste atenção ao movimento do seu abdômen a partir da entrada e saída do ar. Perceba a temperatura do ar ao entrar no seu corpo, observe a temperatura do ar ao sair do seu corpo. Não há necessidade de controlar sua respiração, apenas observe-a, esteja atento ao seu caminho natural. Você por 
um momento pode perceber que pensamentos o distrairão da atenção à sua respiração. Caso isso aconteça, gentilmente retorne sua atenção à respiração". No final deste exercício, a pesquisadora perguntou se houve algum tipo de distração durante o exercício, se o participante pensou em algo diferente do que foi proposto. Caso ele tenha fornecido um exemplo, a pesquisadora então disse: "Veja, é assim que a nossa mente funciona. Estamos constantemente vivendo no momento presente, mas com os nossos pensamentos sobre $o$ passado ou o futuro. Não é interessante perceber como a sua mente funciona?" Esta sessão teve duração de trinta minutos.

Sexta sessão: Ajudar o participante a identificar direções de valores de vida. Esta sessão consistirá em duas etapas: metáfora sobre valores (Hayes, et al., 1999) e conclusão.

\section{A) Metáfora sobre valores}

A pesquisadora explicou que o objetivo desta sessão foi estabelecer relação entre eventos privados e ações rumo aos valores do participante. Para isso, ela disse: "Você já ouviu ou conhece alguém que foi submetido à quimioterapia? Você sabe que em alguns momentos este tratamento é bastante aversivo, as pessoas relatam sentir enjoo e tonturas, eles perdem cabelo e sentem uma série de sintomas desconfortáveis. Mas, mesmo com todas essas implicações, poucas pessoas se recusam a realizar quimioterapia. Você saberia dizer por que as pessoas não se recusam a realizar este procedimento?" O participante pode responder algo do tipo: "Porque a pessoa precisa deste tratamento para ser curado". A pesquisadora continuou dizendo: "Exatamente, porque sentir este desconforto pode significar a cura para 0 câncer em longo prazo e até mesmo melhorar a qualidade de vida do paciente". "Você já esteve, não nesta situação específica, mas em alguma situação similar onde você sentiu algum desconforto por um período de tempo de modo a alcançar algo valioso na sua vida"? A pesquisadora então solicitou que o participante fornecesse dois ou três exemplos que correspondem a estas 
experiências. Se o participante não responder, a pesquisadora pode oferecer outro exemplo: "Por exemplo, quando você visita o dentista, naquele exato momento é doloroso e incômodo, mas você faz isso porque precisa ter uma boca saudável". Imediatamente após este segundo exemplo, a pesquisadora pediu um terceiro exemplo para o participante. Esta etapa teve duração de trinta minutos.

C) Conclusão

Após a primeira etapa, a pesquisadora disse: "Então, o objetivo deste estudo é ajudar pessoas a realizarem o exame de ressonância magnética ao mesmo tempo em que a pessoa vivenciará muito desconforto e pensamentos desagradáveis. Assim, durante a realização do procedimento, mantenha em mente que o tempo que você permanecerá dentro do aparelho será muito importante para a sua saúde. Pense que estes minutos desconfortáveis podem ser fundamentais para o seu futuro, de modo que saberemos muitas informações sobre algo muito valioso: sua saúde. "Esta etapa teve duração de cinco minutos.

Sétima sessão: Ajudar o participante a engajar-se em ações compromissadas com seus valores e permitir que pensamentos, emoções e memórias funcionem não como obstáculos mas como algo que faz parte da vida. Para esta sessão, utilizou-se a metáfora "Zé, o bebum" (Hayes et al.,1999, p. 240).

A pesquisadora iniciou a sessão pedindo para que o participante imaginasse a seguinte situação: "Imagine que você comprou uma casa nova e convidou todos os vizinhos para uma festa. Todos da vizinhança foram convidados, você até colocou um aviso no supermercado. Assim todos os vizinhos apareceram, a festa estava ótima até que chegou Zé, que vive atrás do supermercado, junto ao lixo. Ele é fedorento, e você pensa: "Ah não! Porque ele apareceu? "Mas você disse no aviso: "Todos são bem vindos." Você acha que é possível para você recebê-lo com boas-vindas mesmo sem gostar que ele esteja presente? Você pode dar-Ihe boas-vindas mesmo que você não 
pense bem dele? Você não tem que gostar dele. Você não tem que gostar de como ele cheira, de seu estilo de vida, ou de sua roupa. Você pode ficar envergonhado pelo modo como ele se serve ou como coloca os dedos nos sanduíches. Sua opinião sobre ele, sua avaliação sobre ele, é absolutamente distinta de sua disposição de tê-lo como um convidado em sua casa. Você poderia ter outra opção: decidir que mesmo todos sendo bem vindos, mas não Zé. No entanto, assim que você fizer isto, a festa mudará. Agora você terá que ficar na porta da casa, fazendo guarda para que ele não entre na festa. Ou se você disser: "Tudo bem, você é bem-vindo", mas você não acha isso de verdade, você quer dizer somente que ele é bem-vindo contanto que permaneça na cozinha e não se misture com os outros convidados. Então, você terá que ficar constantemente atento a ele e a festa inteira será a respeito desta vigilância. Neste meio tempo, a vida continua, a festa continua, e você está fazendo guarda para o "desagradável". Isto não é viver. É muito trabalho. A metáfora é, naturalmente, sobre os sentimentos, memórias e pensamentos que aparecem e que você não gosta; eles são apenas Zés na sua vida. A questão é a postura que você toma a respeito dessas experiências internas. Os Zés são bem vindos? Você pode escolher dar-Ihes boas-vindas, mesmo sem gostar deles? Se não, como a festa ficaria?" Esta etapa teve duração de trinta minutos.

\section{Medidas Primárias e Secundárias}

Foram utilizados como critérios de eficácia: permanecer dentro do simulador de Ressonância Magnética por, no mínimo, 30 minutos após o término de cada um dos tratamentos.

As medidas secundárias foram as diferenças estatísticas significativas no Inventário de Claustrofobia, Inventário de Depressão de Beck e Idate.

2.5 Análise estatística 
Os dados provenientes da coleta de dados foram primeiramente inseridos em uma planilha de Excel e processados pelo pacote SPSS (Statistical Package for the Social Sciences). O nível de significância adotado para os testes foi de $5 \%$.

Os dados coletados com o questionário biossociodemográfico, o Questionário de Claustrofobia, o Inventário de Depressão de Beck e o Inventário de Ansiedade IDATE, assim como os escores calculados foram descritos por medidas de tendência central (média, mediana, máximo, mínimo), medida de dispersão (desvio padrão) e de variabilidade. Além disso, foram utilizados os seguintes testes: $Q$ Quadrado, KolmogorovSmirnov, Fisher, Regressão Logística, Teste T, Teste T Pareado e Anova de medidas repetidas.

\subsection{Aspectos éticos}

O projeto foi submetido ao Comitê de Ética para Análise de Pesquisas CAPPesq do Hospital das Clínicas da Faculdade de Medicina da Universidade de São Paulo e aprovado sob protocolo de pesquisa número 0103.11 (ANEXO 7). 


\section{Resultados}

O fluxograma abaixo apresenta cada uma das etapas da pesquisa, assim como a quantidade de participantes alocados em cada etapa e seus desfechos, segundo recomendações do CONSORT (2010):

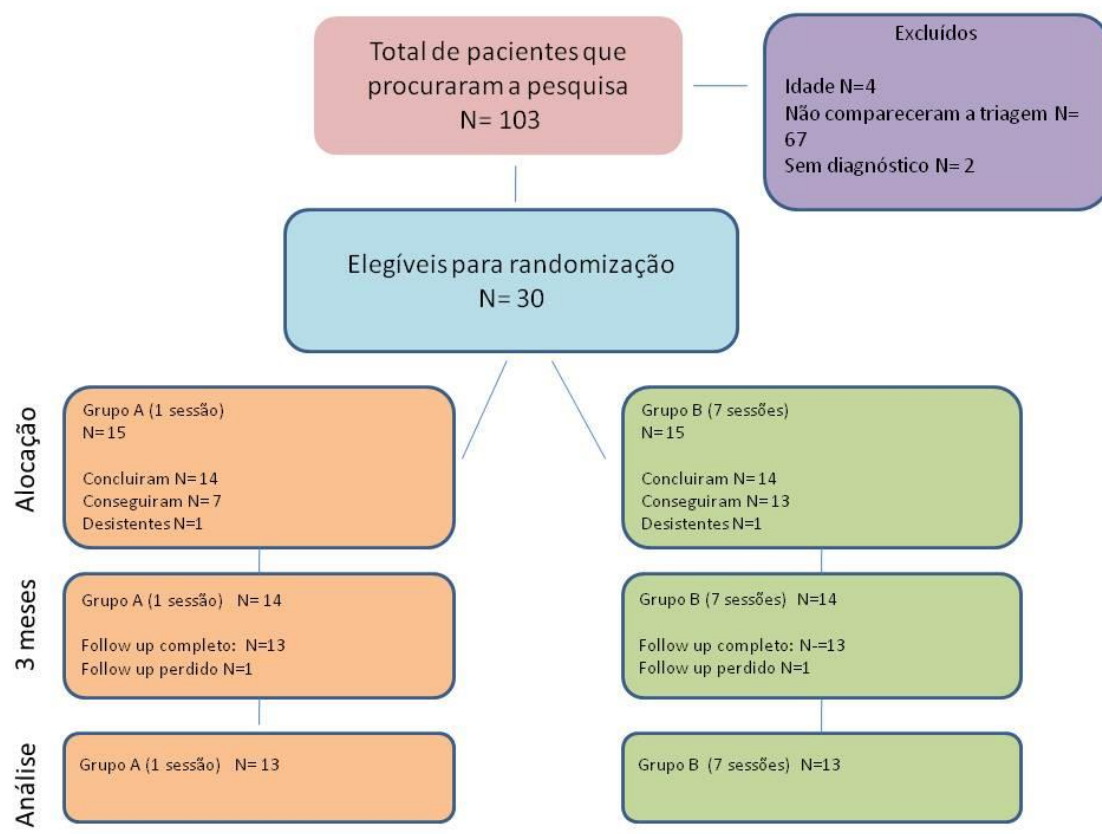

FIGURA 2: Fluxograma com as etapas da pesquisa, segundo CONSORT (2010).

O fluxograma aponta que, no total, 103 pessoas se interessaram em participar do estudo. Setenta e três pessoas não foram incluídas na randomização por questões relacionadas à idade, não preencherem os diagnósticos requeridos e por não terem comparecido à triagem. Dos 30 pacientes randomizados, 14 pessoas finalizam o tratamento em cada um dos grupos. No acompanhamento após 3 meses do estudo, treze pessoas de cada grupo foram incluídas nas análises dos resultados. 


\section{Descrição da amostra}

Os dados da tabela 1 apresentam as características biossociodemográficas dos sujeitos participantes do estudo.

\begin{tabular}{|c|c|c|}
\hline Variáveis & N. & $\%$ \\
\hline \multicolumn{3}{|l|}{ Gênero } \\
\hline Masculino & 10 & 33,3 \\
\hline Feminino & 20 & 66,7 \\
\hline \multicolumn{3}{|l|}{ Idade } \\
\hline $18-30$ & 2 & 6,6 \\
\hline $31-50$ & 16 & 53,3 \\
\hline $51-60$ & 12 & 40,1 \\
\hline \multicolumn{3}{|l|}{ Escolaridade } \\
\hline Ensino fundamental & 2 & 6,6 \\
\hline Ensino médio & 4 & 13,4 \\
\hline Ensino Superior & 24 & 80 \\
\hline \multicolumn{3}{|l|}{ Estado Civil } \\
\hline Solteiro & 8 & 26,6 \\
\hline Casado & 16 & 53,4 \\
\hline Divorciado & 6 & 20 \\
\hline Viúvo & 0 & 0 \\
\hline \multicolumn{3}{|l|}{ Profissão } \\
\hline Área de humanas & 20 & 66,6 \\
\hline Área de Exatas & 4 & 13,4 \\
\hline Área de Biológicas & 6 & 20 \\
\hline \multicolumn{3}{|l|}{$\begin{array}{l}\text { Uso de medicação } \\
\text { psiquiátrica }\end{array}$} \\
\hline Sim & 10 & 33,3 \\
\hline Não & 20 & 66,6 \\
\hline Total & 30 & 100,0 \\
\hline
\end{tabular}

Tabela 1 - Distribuição dos sujeitos, conforme as variáveis biossociodemográficas. 
A maioria dos pacientes era do gênero feminino $(66,7 \%)$, tinha idade entre 31 a 50 anos (53,3\%) e 51 a 60 anos (40,1\%), em sua maioria eram casados $(53,4 \%)$, com profissões na área de humanas $(66,6 \%)$. A maioria dos sujeitos submetidos aos tratamentos não estavam medicados com medicação psiquiátrica $(66,6 \%)$.

Os dados da tabela 2 apresentam as medicações psiquiátricas em uso pelos participantes do estudo.

\begin{tabular}{lll}
\hline Medicação & N. & \% \\
\hline Citalopram & 1 & 10 \\
Cloridrato de Propanolol & 1 & 10 \\
Diazepam & 1 & 10 \\
Escitalopram & 1 & 10 \\
Fluoxetina & 1 & 10 \\
Sertralina & 3 & 30 \\
Paroxetina & 1 & 10 \\
\hline Topiramato & 1 & 10 \\
\hline Total & 10 & 100,0 \\
\hline
\end{tabular}

Tabela 2 - Medicações psiquiátricas em uso.

Os dados da tabela 2 evidenciam o uso da Sertralina por $30 \%$ dos sujeitos participantes. Oito pacientes usavam antidepressivos, um benzodiazepínico e um betabloqueador.

Os dados da tabela 3 apresentam os diagnósticos dos participantes do estudo.

\begin{tabular}{|c|c|c|}
\hline Diagnóstico & N. & $\%$ \\
\hline Fobia específica - RM & 6 & 20 \\
\hline $\begin{array}{l}\text { Fobia específica - espaços } \\
\text { fechados }\end{array}$ & 24 & 80 \\
\hline Total & 30 & 100,0 \\
\hline
\end{tabular}

Tabela 3 - Diagnóstico e distribuição dos participantes.

Em relação aos vinte e quatro participantes com diagnóstico de fobia específica de espaços fechados, dezenove deles temiam exames de ressonância magnética e os outros cinco nunca haviam realizado o exame anteriormente. 
Descrição biossociodemográfica dos dois grupos

A tabela 4 apresenta os dados biossociodemográficos dos sujeitos em cada um dos tratamentos: uma sessão e sete sessões.

\begin{tabular}{llll}
\hline Variáveis & 1 sessão & 7 sessões & P-Valor \\
\hline Gênero & & & 0.700 \\
Masculino & $6(40,0 \%)$ & $4(26,7 \%)$ & \\
$\begin{array}{l}\text { Feminino } \\
\text { Escolaridade }\end{array}$ & $9(60,0 \%)$ & $11(73,3 \%)$ & 1.000 \\
& & & \\
Ensino Fundamental & $2(13,3 \%)$ & $0(0,0 \%)$ & \\
Ensino Médio & $1(6,7 \%)$ & $3(20,0 \%)$ & \\
Ensino Superior & $12(80,0 \%)$ & $13(80,0 \%)$ & \\
Estado Civil & & & \\
& & & \\
Solteiro & $4(26,7 \%)$ & $4(26,7 \%)$ & \\
Casado & $7(46,7 \%)$ & $9(60 \%)$ & 0.700 \\
Divorciado & $4(26,7 \%)$ & $2(13,3 \%)$ & \\
Viúvo & $0(0 \%)$ & 0 & \\
Uso de medicação & & & \\
Psiquiátrica & & & \\
& & $4(26,7 \%)$ & \\
Sim & $6(40 \%)$ & $11(73,3 \%)$ & \\
Não & $9(60 \%)$ & $15(100 \%)$ & \\
Total & $15(100 \%)$ & & \\
\hline
\end{tabular}

Tabela 4 - Dados biossociodemográficos dos grupos de 01 e de 7 sessões.

A tabela 4 mostrou que os grupos foram homogêneos. Em geral, os participantes eram em maioria do sexo feminino (60\% a $73 \%)$, tinham ensino superior $(80 \%)$ e eram casados $(46,7 \%$ a $60 \%)$.

A tabela 5 apresenta a média das idades dos participantes de cada um dos tratamentos: 1 sessão e 7 sessões.

\begin{tabular}{llll}
\hline Variável & 1 sessão & 7 sessões & P-Valor \\
\hline Idade & 47,2 & 44,6 & 0.498 \\
Total & 15 & 15 & \\
\hline
\end{tabular}

Tabela 5 - Média da idade dos participantes dos grupos 1 e 7 sessões.

A tabela 5 mostra que embora a média de idade dos participantes do grupo uma sessão seja de 47,2 anos, e a dos participantes do grupo sete 
sessões de 44,6, através do teste T-Student as médias dos grupos não são diferentes ao nível de 0.05 ( $p=0.498$ ).

A tabela 6 apresenta o diagnóstico dos participantes de cada um dos sujeitos dos grupos de uma e sete sessões, conforme DSM V.

\begin{tabular}{|c|c|c|c|}
\hline Variável & 1 sessão & 7 sessões & P-Valor \\
\hline Diagnóstico & & & 1.000 \\
\hline Fobia específica - RM & $3(20 \%)$ & $3(20 \%)$ & \\
\hline $\begin{array}{l}\text { Fobia específica } \\
\text { espaços fechados }\end{array}$ & $12(80 \%)$ & $12(80 \%)$ & \\
\hline Total & $15(100 \%)$ & 15 (100\%) & \\
\hline
\end{tabular}

Tabela 6 - Diagnóstico dos participantes dos grupos 1 e 7 sessões, segundo DSM V.

Segundo a tabela $6,80 \%$ dos participantes possuem diagnóstico de fobia de espaços fechados, e $20 \%$ possuem diagnóstico de fobia específica de realizar exames de Ressonância Magnética.

Os dados das tabelas 4, 5, 6 evidenciam que dois grupos são homogêneos em relação aos dados biossociodemográficos (gênero, idade, escolaridade, estado civil) e à fobia (uso de medicação e diagnóstico). O teste T-Student para comparação de médias de idade dos grupos foi realizado, pois a variável idade possui distribuição Normal, segundo teste KolmogorovSmirnov. Já para as demais variáveis (categóricas) foi utilizado teste Quiquadrado ou Fischer para avaliar a diferença entre os grupos.

Conclusão do exame no simulador de RM

A tabela 7 apresenta os desfechos de cada um dos grupos, ou seja, quantos sujeitos conseguiram realizar o exame no simulador de Ressonância Magnética após o tratamento e em quais grupos eles participam. A variável SIM indica que o sujeito conseguiu fazer o exame no simulador e a variável NÃO indica que o sujeito não conseguiu realizar o exame do simulador. 


\begin{tabular}{llll}
\hline Variável & 1 sessão & 7 sessões & P-Valor \\
\hline Desfecho & & & 0.033 \\
& & & \\
Sim & $7(50,0 \%)$ & $13(92,9 \%)$ & \\
Não & $7(50,0 \%)$ & $1(7,1 \%)$ & \\
Total & 14 & 14 & \\
\hline
\end{tabular}

Tabela 7 - Desfecho do tratamento dos grupos 1 e 7 sessões.

O grupo sete sessões obteve resultados melhores ( $p=0.033$ ) com $92,9 \%$ dos participantes com desfecho favorável do tratamento, ou seja, conseguiram realizar exame de Ressonância Magnética no simulador enquanto que no grupo 01 sessão, apenas 50\% conseguiu realizar o exame no simulador.

Variáveis biossociodemográficas para cada desfecho

A tabela 8 apresenta as variáveis biossociodemográficas dos participantes de cada um dos desfechos.

\begin{tabular}{|c|c|c|c|}
\hline Variável & Desfecho SIM & Desfecho NÃO & P-Valor \\
\hline Gênero & & & 1.000 \\
\hline Masculino & 7 (78\%) & $2(22 \%)$ & \\
\hline Feminino & $13(68 \%)$ & $6(32 \%)$ & \\
\hline Estado Civil & & & 0.555 \\
\hline Solteiro & $5(62 \%)$ & $3(38 \%)$ & \\
\hline Casado & $12(80 \%)$ & $3(20 \%)$ & \\
\hline Divorciado & $3(60 \%)$ & $2(40 \%)$ & \\
\hline Viúvo & $0(0 \%)$ & $0(0 \%)$ & \\
\hline Uso de medicação & & & 0.400 \\
\hline Psiquiátrica & & & \\
\hline Sim & $6(60 \%)$ & $4(40 \%)$ & \\
\hline Não & $14(78 \%)$ & $4(22 \%)$ & \\
\hline \multicolumn{4}{|l|}{ Diagnóstico } \\
\hline Fobia Específica - RM & $5(100 \%)$ & $0(0 \%)$ & \\
\hline $\begin{array}{l}\text { Fobia espaços } \\
\text { fechados }\end{array}$ & 15 (65\%) & $8(35 \%)$ & \\
\hline Total & 20 & 8 & \\
\hline
\end{tabular}


que tiveram melhor resposta ao tratamento, $78 \%$ eram do sexo masculino, $80 \%$ eram casados, $78 \%$ não faziam uso de medicação psiquiátrica. Cem por cento dos pacientes com fobia específica de Ressonância Magnética foram bem sucedidos no tratamento, enquanto que para os sujeitos com diagnóstico de Fobia de espaços fechados este percentual foi apenas de $65 \%$.

Percentual desfecho SIM (permanência no simulador com sucesso)

A tabela 09 apresenta o percentual de pacientes que conseguiram realizar o exame no simulador de ressonância magnética (desfecho SIM).

\begin{tabular}{llcl}
\hline \multicolumn{3}{c}{ \% Desfecho SIM (n=20) } \\
\hline $\begin{array}{l}\text { Variável } \\
\text { Medo RM }\end{array}$ & $\begin{array}{l}\text { 1 sessão } \\
100 \%\end{array}$ & $100 \%$ & P-valor \\
$\begin{array}{l}\text { Fobia espaços } \\
\text { fechados }\end{array}$ & $36 \%$ & $92 \%$ & 1.000 \\
Total & $50 \%$ & $93 \%$ & 0.009 \\
\hline
\end{tabular}

Tabela 9 - Percentual de pacientes que conseguiram realizar o exame no simulador.

Todos os sujeitos com medo de realizar exames de Ressonância Magnética conseguiram realizar o exame no simulador independente do número de sessões. Já os portadores de fobia de espaços fechados responderam melhor ao tratamento de sete sessões $(92 \%, p=0.009)$ segundo $o$ teste exato de Fischer.

Desistentes

Dois participantes desistiram do tratamento, um pertencia ao grupo uma sessão e outro ao grupo sete sessões. O primeiro foi do sexo feminino, 52 anos, separada e com superior completo. O segundo foi do sexo masculino, 59 anos, casado e com superior completo. $O$ participante do grupo uma sessão solicitou para fazer o exame no simulador em outro dia e não retornou e 0 participante do grupo sete sessões também não compareceu à sessão no 
simulador. No acompanhamento pós três meses de conclusão do estudo, dois participantes não foram localizados, um pertencia ao grupo uma sessão e outro ao grupo sete sessões.

Médias dos inventários: sintomas ansiosos e depressivos

A tabela 10 apresenta os valores obtidos em cada uma das escalas para cada um dos diagnósticos (fobia específica de RM e fobia de espaços fechados), no tempo 1 (triagem).

\begin{tabular}{|c|c|c|c|c|c|}
\hline Escala & Diagnóstico & $\begin{array}{l}\text { Média } \\
\text { (DP) }\end{array}$ & $\begin{array}{c}\text { Intervalo de } \\
\text { confiança } \\
(95 \%)\end{array}$ & Mediana & $\begin{array}{c}\mathrm{p}- \\
\text { valor }\end{array}$ \\
\hline \multirow[t]{2}{*}{ Claustrof_T1 } & $\begin{array}{l}\text { Medo de Ressonância } \\
\text { Magnética }\end{array}$ & $\begin{array}{l}39,83 \\
(21,2)\end{array}$ & {$[17,6 ; 62,0]$} & 40,00 & \multirow[t]{2}{*}{0,004} \\
\hline & Claustro & $\begin{array}{l}67,92 \\
(17,5)\end{array}$ & {$[60,5 ; 75,3]$} & 72,50 & \\
\hline \multirow[t]{2}{*}{ Beck_T1 } & $\begin{array}{l}\text { Medo de Ressonância } \\
\text { Magnética }\end{array}$ & $12,00(7,2)$ & {$[4,4 ; 19,6]$} & 9,00 & \multirow{2}{*}{0,900} \\
\hline & Claustro & $13,04(8,4)$ & {$[9,5 ; 16,6]$} & 11,50 & \\
\hline \multirow[t]{2}{*}{ Idate Est_T1 } & $\begin{array}{l}\text { Medo de Ressonância } \\
\text { Magnética }\end{array}$ & $45,5(3,4)$ & {$[41,9 ; 49,1]$} & 44,50 & \multirow{2}{*}{0,230} \\
\hline & Claustro & $42,63(4,9)$ & {$[40,6 ; 44,7]$} & 43,00 & \\
\hline \multirow[t]{2}{*}{$\begin{array}{c}\text { Idate } \\
\text { traço_T1 }\end{array}$} & $\begin{array}{l}\text { Medo de Ressonância } \\
\text { Magnética }\end{array}$ & $43,83(4,8)$ & {$[38,8 ; 48,9]$} & 43,50 & \multirow{2}{*}{1,000} \\
\hline & Claustro & $44,25(4,8)$ & {$[42,2 ; 46,3]$} & 43,50 & \\
\hline
\end{tabular}

Tabela 10 - escalas $\mathrm{x}$ diagnósticos na triagem.

No Inventário de Claustrofobia $(p=0,004)$, verificou-se que no momento da triagem, os participantes com diagnóstico de fobia de espaços fechados apresentam maior sintomatologia (média 39,83 ) do que os participantes de fobia específica de RM (média 67,92).

A tabela 11 apresenta as médias dos resultados dos Inventários de Claustrofobia, Inventário Beck de Depressão, Idate estado, traço dos grupos uma e sete sessões, antes, depois e após três meses de tratamento. Observa- 
se que os grupos mostraram-se homogêneos em relação aos inventários no início do tratamento. Após o tratamento, observa-se uma diferença significante entre as médias dos grupos no inventário de Claustrofobia $(p=0,014)$. Os resultados do inventário de claustrofobia foram menores para o grupo que fez sete sessões de psicoterapia, indicando que estes pacientes melhoraram mais.

\begin{tabular}{llll}
\hline Variável & $\begin{array}{l}\text { 1 sessão } \\
\text { Média (DP) }\end{array}$ & $\begin{array}{l}\text { 7 sessões } \\
\text { Média (DP) }\end{array}$ & $\begin{array}{l}\text { P-Valor } \\
\text { Entre Grupos }\end{array}$ \\
\hline $\begin{array}{l}\text { Inventário } \\
\text { Claustrofobia }\end{array}$ & & \\
Antes & $64,07(16,07)$ & $63,29(25,45)$ & 0,719 \\
Depois & $56,86(25,68)$ & $34,50(18,72)$ & 0,014 \\
3 meses & $61,31(26,08)$ & $44,85(23,06)$ & 0,101 \\
Inventário & & & \\
Depressão Beck & & & \\
& & & \\
Antes & $14,36(9,94)$ & $12,21(6,02)$ & 0,464 \\
Depois & $12,64(9,58)$ & $8,21(6,14)$ & 0,160 \\
3 meses & $14,15(8,61)$ & $9,38(7,63)$ & 0,148
\end{tabular}

\begin{tabular}{llll} 
Idate estado & & \\
Antes & $43,14(5,37)$ & $42,93(4,37)$ & 0,763 \\
Depois & $43,07(5,06)$ & $44,43(5,21)$ & 0,491 \\
3 meses & $43,85(4,16)$ & $42,77(4,86)$ & 0,550 \\
\hline Idate traço & & & \\
& & & 0,911 \\
Antes & $44,36(4,19)$ & $44,29(5,60)$ & 0,708 \\
Depois & $45,07(5,26)$ & $44,21(6,63)$ & 0,052 \\
3 meses & $45,38(3,45)$ & $41,69(5,51)$ & \\
\hline
\end{tabular}

Tabela 11 - médias dos resultados dos inventários dos grupos 01 e 07 sessões, antes, depois e após 3 meses de tratamento e o p-valor para a comparação da diferença entre médias para cada tempo.

A tabela 12 apresenta a comparação entre as médias dos inventários dentro de cada grupo A e B, entre os tempos avaliados. 


\begin{tabular}{|c|c|c|c|c|c|c|}
\hline Variável & $\begin{array}{c}\text { P-Valor } \\
\text { grupo } 1 \text { sess } \\
\text { (antes } \mathrm{X} \\
\text { depois) }\end{array}$ & $\begin{array}{c}\text { P-Valor } \\
\text { grupo } 1 \text { sess } \\
\text { (antes x } 3 \\
\text { meses) }\end{array}$ & $\begin{array}{c}\text { P-Valor } \\
\text { grupo } 1 \text { sess } \\
\text { (depois x } 3 \\
\text { meses) }\end{array}$ & $\begin{array}{l}\text { P-Valor } \\
\text { grupo } 7 \\
\text { sessoes } \\
\text { (antes } \mathrm{X} \\
\text { depois) }\end{array}$ & $\begin{array}{r}\text { P-Valor } \\
\text { grupo } 7 \\
\text { sessões } \\
\text { (antes x } 3 \\
\text { meses) }\end{array}$ & $\begin{array}{c}\text { P-Valor } \\
\text { grupo } 7 \\
\text { sessões } \\
\text { (depois } \\
\text { x } 3 \\
\text { meses) }\end{array}$ \\
\hline $\begin{array}{l}\text { Inventário } \\
\text { Claustrofobia }\end{array}$ & 0,096 & 0,458 & 0,498 & 0,002 & 0,018 & 0,039 \\
\hline $\begin{array}{l}\text { Inventário } \\
\text { Depressão Beck }\end{array}$ & 0,280 & 0,844 & 0,465 & 0,015 & 0,341 & 0,129 \\
\hline Idate estado & 0,945 & 0,758 & 0,374 & 0,287 & 0,857 & 0,536 \\
\hline Idate traço & 0,674 & 0,679 & 0,766 & 0,975 & 0,123 & 0,144 \\
\hline
\end{tabular}

Tabela 12 - Comparação entre as médias dos inventários dentro de cada grupo, 1 sessão e 7 sessões, entre os tempos avaliados.

Os indivíduos do grupo sete sessões responderam ao tratamento $(p=0,002)$. Isto é mostrado pelo inventário de claustrofobia. Diferenças significativas foram encontradas antes e depois do tratamento e se mantiveram três meses depois.

Já no inventário de Beck, observa-se melhora dos sintomas depressivos ao final do tratamento $(p=0,015)$, porém não há diferença no seguimento de três meses. Os escores deste inventário em geral são baixos (tabela 10).

Os resultados das tabelas 10 e 11 evidenciam que os pacientes do grupo sete sessões apresentaram uma diminuição de cerca de 28 pontos nos escores referentes aos inventários de Claustrofobia $(p=0,002)$ e 4 pontos no inventário de Depressão de Beck $(p=0,015)$.

O gráfico 1 apresenta as médias e intervalo de confiança para o inventário de Claustrofobia nos três tempos, antes do tratamento, depois do tratamento, três meses.

Gráfico 1 - Média e Intervalo de Confiança de 95\% para o Inventário de Claustrofobia segundo as três avaliações. 


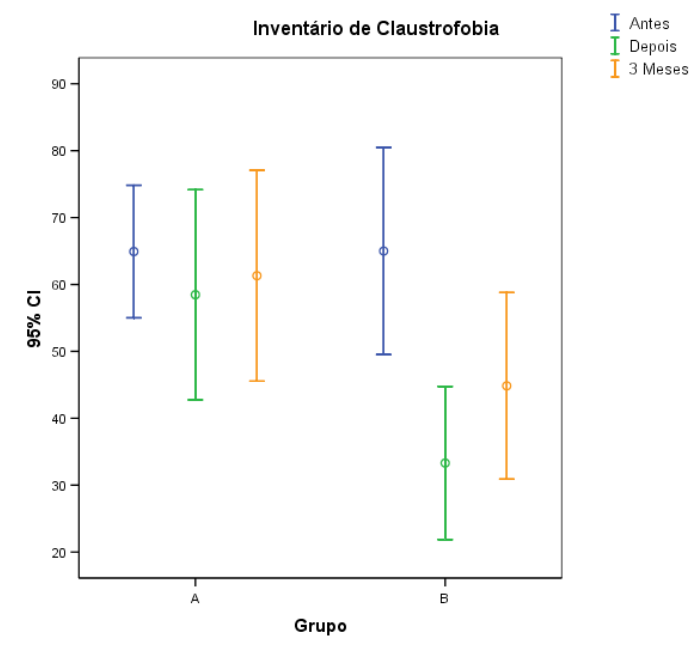

O gráfico 1 aponta com mais clareza os resultados obtidos no grupo de sete sessões de terapia. Para o grupo uma sessão, não houve alteração dos escores médios, mas o grupo sete sessões apresentou diminuição principalmente na avaliação ao final do tratamento e esta melhora se manteve após 3 meses.

A tabela 13 apresenta o resultado da Regressão Logística considerando como variável dependente o desfecho SIM (conseguiu permanecer no simulador), NÃO (não conseguiu permanecer no simulador), e variável independente o escore do inventário de claustrofobia antes.

\begin{tabular}{|c|c|c|}
\hline variável & $\begin{array}{l}\begin{array}{l}\text { Coeficiente de Regressão } \\
\text { (Erro Padrão) }\end{array} \\
\end{array}$ & p-valor \\
\hline $\begin{array}{l}\text { Inventário Claustrofobia } \\
\text { antes }\end{array}$ & $-0.166(0.076)$ & 0.029 \\
\hline Grupo 1 sessão & $-5.067(2.022)$ & 0.012 \\
\hline Constante de Regressão & $15.517(6.363)$ & 0.014 \\
\hline
\end{tabular}

A tabela 13 mostra que mesmo controlando pela variável grupo, o escore inicial do Inventário de Claustrofobia é significante para o desfecho. Observa-se através dos coeficientes de Regressão que quanto maior a pontuação no inventário, menor a probabilidade de desfecho SIM. Entretanto, 
fazer pelo menos sete sessões de terapia aumenta a probabilidade do desfecho positivo desejado.

A tabela 14 mostra o resultado da Regressão Logística considerando como variável dependente o desfecho (SIM, NÃO) e variável independente o escore do inventário Beck antes.

\begin{tabular}{|c|c|c|}
\hline variável & $\begin{array}{l}\begin{array}{l}\text { Coeficiente de Regressão } \\
\text { (Erro Padrão) }\end{array} \\
\end{array}$ & p-valor \\
\hline Inventário Beck antes & $-0.259(0.128)$ & 0.044 \\
\hline Grupo 1 sessão & $-3.355(1.562)$ & 0.031 \\
\hline Constante de Regressão & $6.665(2.654)$ & 0.012 \\
\hline
\end{tabular}

Tabela 14 - Resultado da Regressão Logística considerando como variável dependente o desfecho (SIM, NÃO) e variável independente o escore do inventário Beck antes do tratamento.

A tabela 14 mostra que mesmo controlando pela variável grupo, o escore inicial do Inventário Beck é significante para o desfecho. Observa-se através dos coeficientes de Regressão que quanto maior a pontuação no inventário de sintomas depressivos, menor a probabilidade de conseguir permanecer no simulador. Entretanto, sete sessões de terapia foram benéficas, pois mesmo com escores elevados de sintomatologia depressiva os pacientes foram bem sucedidos na simulação.

Vale ressaltar que ao testar todas as variáveis (biossociodemográficas e inventários) conjuntamente na Regressão Logística, apenas o inventário Beck e o Grupo (número de sessões) permaneceram significantes para a variável de desfecho SIM. Pode-se dizer que através deste estudo é possível estimar a probabilidade de um indivíduo vir a ter desfecho SIM dado o escore Beck antes do tratamento e realizar o tratamento em sete sessões.

Confiabilidade do tratamento oferecido

Duas sessões de cada grupo foram gravadas e encaminhadas para uma terapeuta experiente no modelo de Terapia de Aceitação e Compromisso. Após 
análise dos conteúdos, ela confirma que os passos e as metáforas utilizadas são fiéis ao modelo. 


\section{Discussão}

Algumas considerações sobre a amostra do presente estudo devem ser analisadas. Acerca da análise de gêneros, encontramos um número maior de mulheres, à semelhança do que aponta a literatura (Fredikson et al., 1996). Oitenta por cento dos participantes possuíam ensino superior completo, provavelmente por se tratar de uma população com acesso à internet e que pôde ver a divulgação da pesquisa na página da Universidade de São Paulo. A inscrição para a pesquisa via e-mail também influenciou esta seleção.

Ainda sobre a amostra, verificou-se que os grupos uma e sete sessões eram homogêneos, principalmente com relação à idade, gênero, escolaridade, estado civil e à fobia (uso de medicação e diagnóstico), o que mostra que a randomização realizada foi bem sucedida.

Apesar de a literatura apontar as fobias específicas como um dos transtornos de ansiedade que mais respondem a tratamentos (Barlow, 2002), poucos estudos são realizados com pacientes claustrofóbicos. Em um desses estudos, Ost et al. (1989) apontaram que $90 \%$ dos pacientes claustrofóbicos podem alcançar uma melhora significativa com número reduzido de tratamento psicoterápico (até 10 sessões), dado que tem correspondência com o presente estudo, que apresentou taxas de melhora em $92 \%$ para os participantes do grupo de sete sessões.

Katz et al. (1994) acreditam que os pacientes em uso de medicação psiquiátrica podem apresentar maior tolerância diante dos desconfortos causados pelo exame de Ressonância Magnética. Dos participantes do estudo, $66,7 \%$ não faziam uso de medicação psiquiátrica, ou seja, a maioria dos participantes realizou o exercício no simulador sem esta ajuda. Os desconfortos puderam ser trabalhados durante o tratamento, o que favorece ainda mais o trabalho de aceitação destes. Neste estudo, não houve diferença estatística entre usar ou não a medicação. 
Contrariamente à hipótese levantada no início do trabalho, não houve evidência de que uma sessão de Terapia de Aceitação e Compromisso tenha sido tão eficaz quanto sete sessões. No entanto, algumas questões podem ser levantadas.

O estudo evidencia que o grupo sete sessões obteve resultados melhores ( $p=0.033$ ) com $92,9 \%$ dos participantes com desfecho favorável do tratamento, ou seja, conseguiram realizar exame de Ressonância Magnética no simulador, enquanto no grupo de uma sessão apenas $50 \%$ conseguiram realizar este procedimento.

Há diversas explicações possíveis para a frequência maior de sessões serem necessárias para o sucesso do tratamento: exposição indireta ao aparelho de RM, domínio das habilidades propostas pela ACT e o vínculo com a terapeuta.

O tratamento psicoterápico foi realizado na mesma sala onde se localizava o simulador de RM. Um número maior de sessões pode ter contribuído para uma maior exposição a este estímulo (o simulador), favorecendo a exposição e habituação a possíveis sintomas ansiosos diante deste. Se o tratamento fosse realizado em consultório ou em salas diferentes, o súbito encontro com o aparelho poderia gerar aumento nos níveis de ansiedade e trazer maiores dificuldades para a sessão final no simulador.

Um número maior de sessões também contribui para o desenvolvimento de um melhor domínio dos princípios terapêuticos da ACT por parte do participante. Para os que participaram de apenas uma sessão, estes princípios foram apenas brevemente trabalhados. Estudos futuros poderiam medir 0 conhecimento dos princípios adquiridos durante o tratamento.

Outro aspecto importante é sobre o vínculo estabelecido entre terapeuta e cliente. $O$ fato de os participantes do grupo de sete sessões permanecerem mais tempo em contato com o tratamento e a terapeuta pode ter favorecido o desenvolvimento de maior vínculo e segurança, e este fato ter trazido um desfecho mais favorável ao tratamento. 
Kazdin (2006) descreve que décadas de pesquisas em psicoterapia identificaram que existem influências do paciente, do terapeuta e da relação entre eles que podem alterar o resultado da psicoterapia. Ele aponta a relação terapêutica, a catarse, o acolhimento do terapeuta, o aprendizado, a mudança de expectativas como alguns aspectos que contribuem para um bom desenvolvimento e sucesso da psicoterapia. No entanto, ainda há poucas evidências empíricas do que exatamente contribui para o êxito do tratamento e por que e como as mudanças ocorrem. Sendo assim, futuros estudos poderiam considerar o vínculo entre terapeuta e cliente como variável significativa para o desfecho do tratamento.

A literatura discute o conceito de resultados finais (desfecho) nos seus aspectos técnicos, clínicos, políticos e ideológicos, propondo métodos para medi-los e discutindo como as evidências seriam levantadas (Carter, 2006). Para este autor, existem muitos objetivos possíveis e resultados finais desejados ou esperados da psicoterapia, e por vezes parece que existem tantas medidas de objetivos e resultados finais quantos são os resultados finais possíveis. Em nossa amostra, dos trinta participantes, vinte e cinco deles tinham medo do exame RM. Desses, seis tinham necessidade premente de realizá-lo e, num seguimento nove meses depois do tratamento, quatro foram bem sucedidos na realização do exame. Supomos que uma amostra mais homogênea poderia ter trazido resultados diferentes, por exemplo se todos os participantes tivessem dificuldade para fazer a RM, ou se os desfechos fossem individualmente definidos.

Carter (2006) lista ainda algumas medidas de resultados finais: autoestima, término precoce, mudança global, severidade dos sintomas, funcionamento interpessoal, severidade da adição, mudança da perturbação, relações com terceiros, relações sociais, indecisão, crescimento pessoal, ajustamento sexual, problemas interpessoais, estilos de defesa, empregabilidade, estado civil, autoconceito, sintomas de ansiedade, adesão à medicação, qualidade de vida, hospitalização, produtividade e satisfação com o tratamento. Estas medidas poderiam ser levadas em consideração em trabalhos futuros. 
Esta preocupação com os resultados em psicoterapia nos remete à importância da ampliação do conhecimento clínico cientificamente validado, ou seja, pesquisas de eficácia e efetividade das terapias psicológicas, pelo menos para algumas formas de terapia relacionadas a orientações teóricas que aceitam mensuração de resultados (Starling, 2010). Além da preocupação com os resultados, é importante também a pesquisa sobre os efeitos psicoterapêuticos em longo prazo. Lambert e Archer (2006) relatam que dos clientes que entram em terapia psicológica, de 5 a $10 \%$ deterioram durante $o$ tratamento e de 15 a $25 \%$ não apresentam benefícios mensuráveis. Um índice de remissão de melhora foi identificado neste estudo quando analisamos 0 inventário de Depressão de Beck no segmento três meses $(p=0,129)$.

Ainda sobre a questão dos resultados em psicoterapia, alguns deles estão interessados em medidas mais específicas, tais como o número de sessões necessárias para que ocorram melhoras significativas. Estudos futuros sobre um número intermediário entre uma e sete sessões seria relevante.

Com relação ao desfecho, cem por cento dos pacientes com fobia de Ressonância Magnética foram bem sucedidos no tratamento, enquanto para os sujeitos com diagnóstico de fobia de espaços fechados este percentual foi de apenas $65 \%$. Para os pacientes com diagnóstico de fobia de espaços fechados, muitos precisaram de sete sessões para realizar a simulação. Este dado mostra que o diagnóstico de fobia de Ressonância Magnética pode apresentar sintomatologia mais leve ( $p=0,004$, Questionário de Claustrofobia média $=39,83$ ) que a de fobia de espaços fechados (Questionário de Claustrofobia média $=67,92$ ), favorecendo melhoras significativas com um número reduzido de sessões. Assim sendo, é possível dizer que portadores de fobia de Ressonância Magnética podem se beneficiar com apenas uma sessão de Terapia de Aceitação e Compromisso.

Provavelmente, a alta frequência de indivíduos com fobia específica de espaços fechados (80\%) na amostra aponta para uma maior gravidade e maior probabilidade de esquiva do exame no simulador, o que poderia explicar por que a maioria dos indivíduos respondeu principalmente no tratamento mais prolongado (sete sessões). Ainda assim, considerando a alta prevalência deste 
diagnóstico entre os indivíduos que se recusam a realizar o exame ou necessitam de sedação para 0 procedimento, pode-se esperar que estas pessoas se beneficiarão de um tratamento mais prolongado.

A resposta positiva ao grupo de sete sessões também pode ser observada na avaliação de follow-up, uma vez que apresenta uma melhora duradoura no Inventário de claustrofobia. O grupo de tratamento de uma sessão teve uma frequência de falhas mais alta no desfecho primário (realizar a simulação) e também não mostrou nenhuma melhora nos inventários, o que apoia a superioridade do tratamento de sete sessões. No entanto, o presente estudo mostra resultados encorajadores do tratamento de sete sessões. Treze dos quinze pacientes $(86,6 \%)$ completaram com sucesso a simulação de ressonância magnética, e as melhorias no questionário de claustrofobia foram mantidas três meses após o tratamento. Isto sugere que, embora mais prolongada, esta modalidade de tratamento pode ser altamente satisfatória e pode ser considerada uma alternativa segura e eficaz para estes indivíduos.

A Terapia de Aceitação e Compromisso recebe críticas por não ser um modelo de psicoterapia cujo foco é a diminuição dos sintomas (no caso deste trabalho, fóbico - ansiosos) dos pacientes. A ênfase não seria o trabalho para a diminuição dos sintomas de taquicardia, falta de ar ou esquiva fóbica e sim a aprendizagem de como lidar com tais sintomas no momento em que eles aparecem. Esta é uma abordagem psicoterápica nova, em que a ênfase não é na diminuição de sintomas e cura de doenças e, sim, no manejo delas para melhoria da qualidade de vida. No entanto, apesar de o objetivo da terapia de Aceitação e Compromisso não ser a diminuição de sintomas, observou-se diminuição dos mesmos, tanto ansiosos quanto depressivos.

A consideração da diminuição dos sintomas certamente favorece a discussão sobre o modelo psicoterapêutico utilizado em questão ser eficaz ou não. No entanto, olhar apenas a diminuição dos sintomas não seria suficiente para o complexo entendimento de como essas mudanças ocorrem (Kazdin, 2006). 
A Terapia de Aceitação e Compromisso é um modelo terapêutico que apresenta estudos científicos sobre sua eficácia no tratamento de diversos transtornos mentais. Publicações sobre fobias de espaços fechados e ACT não foram encontrados, no entanto, evidências na literatura apontam este modelo como eficaz para o tratamento de outros transtornos ansiosos (Eifert e Forsyth, 2005; Eifert e Heffner, 2003; Forman et al., 2012; Hoffman et al., 2013).

Observou-se que o modelo terapêutico para tratamento das fobias com maior número de publicações na literatura é o comportamental e a terapia cognitivo-comportamental (Barlow e Cerny, 1988; Clark e Beck, 1988) demonstrando sua eficácia e efetividade. A terapia cognitivo-comportamental é até agora o modelo dominante entre as publicações sobre 0 tratamento dos transtornos ansiosos. No entanto, há um aumento no número de publicações com novas formas de terapia, como é o caso das terapias da terceira onda (Ost, 2008). Este mesmo autor, entretanto, enfatiza a necessidade de estudos mais aprimorados dessas terapias, principalmente para $\circ$ tratamento de diferentes desordens psicológicas.

A Terapia de Aceitação e Compromisso vem ganhando atenção da comunidade científica devido a um número crescente de publicações sobre sua efetividade no tratamento de doenças mentais. Além das contribuições para o tratamento da ansiedade, o uso desta para o tratamento de outros transtornos também foram desenvolvidos, como para sintomas psicóticos (Gaudiano e Herbert, 2006), dor crônica (Hayes e Duckworth, 2006) e abuso de substâncias (Hayes et al., 2004). Outros estudos poderiam aprofundar o uso deste modelo para o tratamento da fobia de espaços fechados.

Pontos fortes do estudo

Este estudo mostrou que a Terapia de Aceitação e Compromisso foi eficaz no tratamento da fobia de espaços fechados, principalmente se for realizada em sete sessões. 
A randomização adequada com grupos homogêneos quanto às variáveis demográficas e clínicas e curto espaço de tempo entre o tratamento e os resultados podem sugerir que os desfechos obtidos podem ser devido à intervenção. Mas também devemos considerar o vínculo terapêutico, a presença do simulador durante todas as sessões e o conhecimento dos princípios da ACT como fatores relacionados ao sucesso do tratamento. Além disso, os amplos critérios de inclusão permitiram a seleção de uma amostra com mais semelhança com a prática clínica, e os resultados assim rendendo uma validade externa superior.

O inventário de claustrofobia utilizado evidenciou que os indivíduos do grupo sete sessões responderam ao tratamento $(p=0,002)$ e mostrou diferenças significativas encontradas antes e depois do tratamento e que se mantiveram três meses depois no tratamento finalizado. Tendo em consideração que quanto maior o tempo decorrido desde o início da intervenção menos parcimonioso seria atribuir eventuais efeitos à terapia, a rapidez com que os efeitos se apresentam a partir do início da intervenção fortalece a confiabilidade da atribuição de eventuais melhoras à psicoterapia (Starling, 2010).

Limitações do estudo

Algumas limitações do estudo devem ser consideradas. A primeira diz respeito a não utilização de linha de base, ou seja, os pacientes não foram testados no simulador antes da realização do procedimento terapêutico. Neste sentido, não se sabe se eles teriam realizado o exame no simulador sem a realização do tratamento.

Outra limitação foi sobre o estudo não ser cego e ter o mesmo terapeuta atuando nos dois grupos.

Sobre a não conclusão da simulação do exame, outras variáveis desconhecidas podem ter influenciado no resultado, como a presença de outro diagnóstico de transtorno mental. A indicação médica para realizar o exame 
também pode ter influenciado a motivação para concluir a simulação, principalmente se há uma hipótese diagnóstica mais séria envolvida.

O estudo também não procurou verificar a satisfação dos participantes com o tratamento e o vínculo com o terapeuta, dado que poderia ter sido investigado através de questionários de satisfação.

Embora seja provável que essas falhas possam ter sido tendenciosas para o desfecho do estudo, os resultados obtidos ainda mostram contradição com a hipótese nula principal.

Os resultados sugerem que os participantes com diagnóstico de fobia de Ressonância Magnética podem se beneficiar com uma sessão de Terapia de Aceitação e Compromisso, mas um estudo com amostra maior se faz necessário.

Um estudo comparando a Terapia de Aceitação e Compromisso com Terapia cognitivo-comportamental e com placebo poderia também ser recomendado. Estudos sobre o risco e custo-benefício poderiam ser considerados para comparar psicoterapia, sedação e outras estratégias. Estudos futuros também poderão identificar um número intermediário entre uma e sete sessões.

\section{Conclusão}

A Terapia de Aceitação e compromisso foi eficaz no tratamento da fobia de espaços fechados. $O$ tratamento em sete sessões trouxe melhora para $100 \%$ dos pacientes com diagnóstico de fobia de Ressonância Magnética e para $92 \%$ dos pacientes com fobia de espaços fechados. Pacientes com diagnóstico de fobia de Ressonância Magnética melhoraram com uma sessão. 
Amaro Junior E, Yamashita H. Aspectos básicos da tomografia computadorizada e ressonância magnética. Revista Brasileira de Psiquiatria. 2001; 23: 2-3

Andery MAA. O modelo de seleção por competências e a subjetividade. In: Banaco RA. Sobre Comportamento e Cognição. Santo André: Arbytes; 1997. 1v.

American Psychiatry Association. Manual Diagnóstico e Estatístico de Transtornos Mentais. 5 ed. Porto Alegre: Artmed; 2014.

American Psychiatry Association. Manual Diagnóstico e Estatístico de transtornos mentais IV - TR. Porto Alegre: Artmed; 2002.

Antony MM, Moras K, Meadows EA, Di Nardo PA, Utech JE, Barlow DH. The diagnostic significance of the functional impairment and subjective distress criterion: an illustration with the DSM III-R anxiety disorders. J psycho and behav assess, 1994; 16: 253-263.

Arch, JJ, Craske, MG. Acceptance and Commitment Therapy and Cognitive Behavioral Therapy for Anxiety Disorders: different treatments, similar mechanisms? Clinic Psychol Sci Prac. 2008 15: 263-279.

Ball W, Holland $S$. The fear of new technology: a naturally occurring phenomenon. Am J Bioeth. 2009; 9: 14-6.

Barlow DH, Cerny JA. Psychological treatment of panic. New York: Guilford Press; 1988.

Barlow DH. Anxiety and its disorders: The nature treatment of anxiety and Panic. New York: The Guilford Press; 2002.

Beck AT, Emery G, Greenberg RL. Anxiety disorders and phobias: a cognitive perspective. New York: Basic Books; 1985. 
Beck AT, Ward CH, Mendelson M, Mock J, Erbaugh G.An Inventory for Measuring Depression. Archives of General Psychiatry. 1961; 4:53-63.

Biaggio AMB, Natalicio L. Manual para o inventário de ansiedade Traço-Estado (IDATE). Rio de Janeiro, CEPA; 1979.

Brown LA, Forman EM, Herbert JD, Hoffman KL, Yuen EK, Goetter, EM. A randomized controlled trial of acceptance-based behavior therapy and cognitive therapy for test anxiety: A pilot study. Behav Modif 2011; 35: 31-53.

Busnello ED, Pereira MP, Knapp WP, Salgado CAI, Taborda JGV, Knijnik L et al. Morbidade psiquiátrica na população urbana de Porto Alegre. Jornal Brasileiro de Psiquiatria. 1992; 41(10): 507-512.

Carter, JA. Theoretical pluralism and technical eclecticism. In Goodherat CD, Kazdin, AE, Stenberg, RJ (eds). Evidence-based psychotherapy. Washington: American Psychological Association; 2006.

Chapman, TF. The epidemiology of fears and phobias. In Davey G. Phobias: a handbook of theory, research and treatment. London: Wiley; 1997.

Choy Y, Stein MB, Hermann R. Acute procedure anxiety in adults: course, screening, assessment and differential diagnosis. Clinical Psychology Review. 2013; 27:196-8.

Clark DM, Beck AT. Cognitive approaches. In Last CG, Hersen M. (Eds). Handbook of anxiety disorders. New York: Pergamon Press; 1988.

Costa N. Terapia Analítico-Comportamental: dos fundamentos filosóficos à relação com o modelo cognitivista. Santo André: Esetec; 2002.

Craske MG. Anxiety disorders: Psychological approaches to theory and treatment. Boulder: Westview Press; 1999. 
Craske MG., Barlow DH. Panic disorder and agoraphobia. In Barlow DH (Ed.) Clinical Handbook of psychological disorders: A step-by-step treatment manual. New York: Guilford Press; 1993.

Dunn G, Sham P, Hand D. Statistics and the Nature of Depression. Psych Med. 1993; 23:871-889.

Eifert GH, Forsyth JP. Acceptance and Commitment Therapy for anxiety disorders: A theoretical integration and synthesis of laboratory research. Psychological Bulletin 2005; 130: 355-391.

Eifert GH, Heffner M. The effects of acceptance versus control contexts on avoidance of panic-related symptoms. J Behav Therapy and Experim Psych. 2003; 34 (3-4): 293-312.

Enders J, Zimmermann E, Rief M, Klingebiel R, Asbach P. Reduction of claustrophobia during magnetic resonance imaging: methods and design of the claustrophobic randomized controlled trial. AMC Med Imaging 2001;11:4-9.

Eshed I, Althoff CE, Hamm B, Hermann KG. Claustrophobia and premature termination of magnetic resonance imaging examinations. J Magn Reson Imaging. 2007; 26: 401-4.

Fishbain D, Goldberg M., Labee E. MR imaging as a trigger for persistent claustrophobia. American J Radiol.1989; 152:653.

Fyer AJ, Mannuzza S, Gallops MS. Familial transmission of simple phobias and fears: a preliminary report. Arch Gen Psychiatry. 1990; 47: 252-6

Fredrikson M, Annas P, Fischer H, Wik G. Gender and age differences in the prevalence of specific fears and phobias. Behav Research Therapy. 1996; 34: 33-9.

Forman EM, Shaw JA, Goetter EM, Herbert JD, Park JA. Long-term follow-up of a randomized controlled trial comparing Acceptance and Commitment Therapy and standard Cognitive Behavior Therapy for anxiety and depression. Behav Therapy. 2012; 43: 801-11. 
Garcia-Pallacios J, Hoffman HG, Richards TE, Seibek EJ, Sharar SR. Use of Virtual Reality Distraction to reduce Claustrophobia symptoms during mock magnetic resonance imaging brain scan: a case report. Cyber Psychol and Behav. 2007; 10: 3.

Gaudiano BA, Hebert JD. Acute treatment of inpatients with psychotic symptoms using acceptance and commitment therapy: Pilot results. Behav Research and therapy. 2006: 44: 415-37.

Gilbert P. Compassion: conceptualization, research and use in Psychotherapy. London, Routledge; 2005.

Granet R, Gelber L. Claustrophobia during MR imaging. N J Med. 1990; 87: 479-82.

Gorenstein C, Andrade L. Validation of a portuguese version of the Beck Depression Inventory and the State-Trait Anxiety Inventory in brazilian subjects. Braz J M Biol Research. 1996; 29: 453-7.

Gouveia V, Medeiros E, Gouveia R, Santos W, Diniz P. Cuestionario de Claustrofobia: Evidencias de su validez y fiabilidad. Interamerican J of Psychol. 2008; 42(3): 604-10.

Gratz KL, Gunderson JG. Preliminary data on an Acceptance-based emotion regulation group intervention for deliberate self-harm among women with borderline personality disorder. Behav Therapy. 2006: 37: 25-35.

Gregg JA, Callaghan GM, Hayes SC, Glenn-Lawson JL. Improving diabetes self-management through acceptance, mindfulness, and values: a randomized controlled trial. J Consul and Clinical Psychol. 2007; 75: 336-43.

Hayes SC, Barnes-Holmes D, Roche B. Relational frame theory: A post skinnerian account of human language and cognition. New York: Plenum Press; 2001.

Hayes SC, Bissett RT, Korn Z, Zettle, RD, Rosenfarb I, Cooper L, Grundt, A. The impact of acceptance versus control rationales on pain tolerance. The Psychol Record.1999; 49: 33-47. 
Hayes SC, Duckworth M. Acceptance and Commitment therapy and traditional Cognitive Behavior Therapy approaches to pain. Cognitive and Behavior Practice. 2006; 13: 185-7

Hayes SC, Follette, VM, Linehan M. Mindfulness and acceptance: Expanding the cognitive behavioral tradition. New York: Guilford Press; 2004.

Hayes SC, Luoma JB, Bond FW, Masuda A, Lillis J. Acceptance and commitment therapy: model, processes and outcomes. Behav Research \& Therapy. 2006; 44: 1-25

Hayes SC, Strosahl K, Wilson KG. Acceptance and Commitment Therapy: An experiential approach to behavior change. New York: Guilford Press; 1999.

Hayes SC, Zettle R, Rosenfarb I. Rule-following. In Hayes SC. Rule-Governed Behavior: Cognition, contingencies, and instructional control. New York: Plenum Press; 1989.

Hayes SC, Wilson, KG, Afari N, McCurry S. The use of Acceptance and Commitment therapy in the treatment of agoraphobia. In abstracts of meeting of the Association for the Advancement of Behavior Therapy. June 12-13, 1990. San Francisco, USA.

Hayes SC, Wilson KG, Gifford EV, Bisset R, Piasecki, M. A preliminary trial of twelve-step facilitation and acceptance and commitment therapy with polysubstance-abusing methadone-maintained opiate addicts. Behav Therapy.2004; 35: 667-88.

Healy HA, Barnes-Holmes Y, Barnes-Holmes D, Keogh C, Luciano C, Wilson K. An experimental test of a cognitive defusion exercise: Coping with negative and positive self-statements. The Psychological Record.2008; 58: 623-40.

Hoffman D, Rask CU, Hedman E, Frostholm L. Internet-delivered Acceptance and Commitment Therapy for health anxiety: a randomized controlled trial. In abstracts of the meeting of the 11 Association of Contextual Science World Conference. Julho 09-12, 2013. Sydney, Australia.

Hollander E, Simeon D. Transtornos de Ansiedade. Porto Alegre: Artmed; 2004. 
Jones MC. The elimination of children's fears. J.of Experim Psychol. 1924;7 (5): 382-90.

Juárez GMR, Gois CFL, Sawada NO. Ansiedade e medo: avaliação crítica dos artigos na área da saúde. Proceedings of the 8 Brazilian Nursing Communication Symposium; 2002: SciELO Brasil.

Kabat-Zinn J. Full catastrophe living using the wisdom of your body and mind to face stress, pain and illness. New York: Delacorte; 1990

Kalish M. From Behavioral science to behavior modification. New York: McGraw Hill Book Company; 1981.

Knapp, P. e cols. Terapia Cognitivo-Comportamental na Prática Psiquiátrica. Porto Alegre: Artmed; 2004.

Kashdan TB, Farmer A, Adams L, Ferssizidis P, McKnight PE, NezlekJB. Distinguishing healthy adults from people with social anxiety disorder: Evidence for the value of experiential avoidance and positive emotions in everyday social interactions. J of Abnormal Psychol. 2013; 122:645-55.

Katz R, Wilson L, Frazer N. Anxiety and its determinants in patients undergoing magnetic resonance imaging. J Behav Therapy and Exp. Psych. 1994; 25, (2): 131-4.

Kazdin, AE. Assessment and evaluation in clinical practice. Washington DC: American Psychological Association; 2006.

Kendler KS, Neale MC, Kessler RC. The genetic epidemiology of phobias in woman: the interrelationship of agoraphobia, social phobia, situational phobia and simple phobia. Arch Gen Psychiatry. 1992; 49: 273-81.

Keller RS. Aprendizagem: teoria do reforço. São Paulo, E.P.U; 1973.

Kessler RC, Nelson CB, McGonagle KA, Liu J, Swartz M, Blazer DG. Comorbidity of DSM-III-R major depressive disorder in the general population: results from the US National Comorbidity Survey. $\mathrm{Br} J$ Psychiatry 1996; 168(30): 17-30. 
Kilborn LC, Labbe EE. Magnetic resonance imaging scanning procedures: development of phobic response during scan and at one month follow-up. $J$ Behav Med. 1990; 13: 391-401.

Kirkpatrick DR. Age, gender, and patterns of common intense fears among adults. Behav Research and Therapy.1984; 22: 141-50.

Klonoff E, Janata J, Kaufman B. The use of systematic desensitization to overcome resistance to magnetic resonance imaging (MRI) scanning. J Behav.Ther \& Exp. Psychiat 1986; 17 (3): 189-92.

Kohlenberg RJ, Tsai M. Functional analitic psychotherapy: creating intense and curative therapeutic relationships. New York: Plenum; 1991.

Lambert, MJ, Archer A. Research findings on the effects of psychotherapy and their implications for practice. In Goodheart CD, Kazdin AE, Stenberg RJ. (eds). Evidence-based psychotherapy. Washington: American Psychological Association; 2006.

Leahey TH. A history of Psychology: main currents in psychological thought. New Jersey: Prentice-Hall; 1980.

Levitt JT, Brown TA, Orsillo SM, Barlow DH. The effects of acceptance versus suppression of emotion on subjective and psychophysiological response to carbon dioxide challenge in patients with panic disorder. Behavior Therapy. 2001, 32:21-8.

Linehan MM. Cognitive-behavioral treatment of borderline personality disorder. New York: Guilford Press, 1993

Lundgren T, Dahl J, Melin L, Kies B. Evaluation of acceptance and commitment therapy for drug refractory epilepsy: a randomized controlled trial in South Africa - a pilot study. Epilepsia.2006; 47: 2173-9.

Marks, I. Fears, fobias and rituals. New York: Oxford University Press, 1987.

Margis R, Picon P, Cosner AF, Silveira RO. Relação entre estressores, estresse e ansiedade. Revista de Psiquiatria do Rio Grande do Sul. 2003; 25 (1): 65-74 
Marshall J, Martin T, Downie J, Malisza K. A comprehensive analysis of MRI research risks: In support of full disclosure. Canadian $\mathrm{J}$ of Neurol Sciences. 2007; 34: 11-7.

Martinez MA, Garcia A, Botella C. Propriedades psicométricas del cuestionario de Claustrofobia em población española. Psicoteha. 2003; 15: 673-8.

McGlynn FD, Smitherman TA, Hammel JC, Lazarte AA. Component fears of claustrophobia associated with mock magnetic resonance imaging. J Anxiety Disord. 2001; 21: 367-80.

Medelez JC, McCrank E. Anxiety-related reactions associated with Magnetic Resonance Imaging examinations. JAMA.1993; 270 (6): 141-50.

Murphy K, Brunberg JA. Adult claustrophobia, anxiety and sedation in MRI. Magn Reson Imaging. 1997; 15: 51-4.

Nardi, AE. Comentários do debatedor: escalas de avaliação de ansiedade. Revista de Psiquiatria Clínica. 1998; 25 (6).

Ost LG. Efficacy of the third wave of behavioral therapies: A systematic review and meta-analysis. Behav Research and Therapy.2008; 46: 296-321.

Ost LG, Sterner U, Fellenius J. Applied tension, applied relaxation and the combinations in the treatment of blood phobia. Behav Research and Therapy.1989; 27: 109-21.

Ost LG. The Claustrophobia Scale: a psychometric evaluation. Behav Research Therapy 2006; 45: 1053-64.

Páez-Blarrina, M, Luciano C, Gutiérrez-Martínez O, Valdivia S, Ortega J, Rodríguez-Valverde M. The role of values with personal examples in altering the functions of pain: comparison between acceptance-based and cognitivecontrol-based protocols. Behav Research and Therapy 2008; 46: 84-97.

Phillips, S, Deary, I. Interventions to alleviate patient anxiety during Magnetic Resonance Imaging: a review. Radiography 1995; 1: 29-34. 
Rachman S, Taylor S. Analyses of claustrophobia. J of Anxiety disorders. 1993; 7 (14): $51-4$

Radomsky AS, Rachman S, Thordarson DS, Mclsaac HK, Teachman BA. The Claustrophobic Questionnaire. J of Anxiety Disord.2001; 15 (4): 287 - 97.

Roemer L, Orsillo SM, Salters-Pedneault K. Efficacy of an acceptance-based behavior therapy for generalized anxiety disorder: Evaluation in a randomized controlled trial. J Consulting and Clin Psychol. 2008; 76: 1083-9.

Rosenberg DR, Sweeney JA, Gillen JS, Kim J, Varanelli MJ, O'hearn K.M., Erb PA, David D, Thulbern KR. Magnetic Resonance imaging of children without sedation: preparation with simulation. J Am Academy of Child and Adolescent Psychiatry. 1997; 36: 853-9

Sanches IJ. Sobreposição de imagens de termografia e Ressonância Magnética: uma nova modalidade de imagens médica tridimensional. [tese]. Paraná: Universidade Tecnológica Federal do Paraná; 2009.

Segal ZV, Teasdale JD, Williams JMG. Mindfulness based cognitive therapy: Theorical rationale and empirical status. In Hayes SC, Follete VM, Linehan M (eds). Mindfulness, acceptance and relationship. New York: The Gilford Press; 2004.

Shellock F, Kanal E. Magnetic resonance: bioeffects, safety and patient management. New York: Raven Press; 1994.

Silva APL. Validação do questionário de claustrofobia em pacientes submetidos à ressonância magnética. [Tese]. São Paulo: Universidade de São Paulo; 2013.

Skinner, B.F. Ciência e comportamento humano. 4a ed. São Paulo: Martins Fontes; 1978.

Slifer K, Penn Jones K., Cataldo M., Cooner R, Zerhoubi E. Music enhances patient comfort during MRI. Am J Research. 2001; 156: 403.

Spielberger CD, Gorsuch RL, Lushene RE. State-trait anxiety inventory: STAI. New York: Consulting Psychologists Press; 1970. 
Stahl B, Goldstein E. A Mindfulness-based stress reduction workbook. Oakland: New Harbinger; 2010.

Starling RR. Prática controlada: medidas continuadas e produção de evidências empíricas em práticas analítico-comportamentais. [Tese]. São Paulo: Universidade de São Paulo; 2010.

Terra MB, Garcez JP, Noll B. Fobia específica: um estudo transversal com 103 pacientes tratados em ambulatório. Revista Psiquiatria Clinica USP. 2007; 34 (2): 68-73.

Thorpe S, Salkovskis, PM, Dittner A. Claustrophobia in MRI: the role of cognitions. Magn Reson Imaging. 2008; 26: 1081-8.

Todorov, J. C. Evolução de conceitos na análise do comportamento. Psicologia: Reflexão e Crítica. 2004; 17(2).

Torpy JM, Lynm CMA, Glass RM. Magnetic Resonance Imaging. JAMA. 2009; 302 (23): 2614

Twohig MP, Hayes SC, Masuda A. Increasing willingness to experience obsessions: Acceptance and Commitment Therapy as a treatment for obsessive-compulsive disorder. Behav therapy. 2006; 37: 3-13.

Velloso LGC, Duprat ML, Martins R, Scoppetta L. Hipnose para controle de claustrofobia em exames de ressonância magnética. Radiol Bras. 2010; 43 (1): 19-22.

Zettle RD. Acceptance and commitment therapy (ACT) versus systematic desensitization in treatment of mathematics anxiety. The Psychological Record. 2003; 53: 197-215.

Weinreb J, Maravilla K., Peshock R, Payne J. Magnetic resonance imaging: improving patient tolerance and safety. American Journal Research.1984; 143: $1285-7$.

Wilson, KG, Soriano MCL. Terapia de Aceptación y Compromiso (ACT): Un tratamiento conductual orientado a los valores. Ediciones Pirámide, 2002.

Formatado: Espanhol (Espanha - Tradicional) Formatado: Espanhol (Espanha - Tradicional)

Formatado: Espanhol (Espanha - Tradicional) Formatado: Espanhol (Espanha - Tradicional) Formatado: Espanhol (Espanha - Tradicional) 
Wood B, Mcglynn FD. Research on Post treatment return of Claustrophobic fear, arousal and avoidance using Mock Diagnostic Imaging. Behav Modification. 2000; 24 (3): 379-94.

Woods DW, Wetterneck CT, Flessner CA.A controlled evaluation of acceptance and commitment therapy plus habit reversal for trichotillomania. Behav Research and Therapy. 2006; 44: 693-6.

Wolpe J. Prática da terapia comportamental. São Paulo: Brasiliense; 1973.

Formatado: Fonte: $12 \mathrm{pt}$ Formatado: Fonte: $12 \mathrm{pt}$

Formatado: Fonte: $12 \mathrm{pt}$

Formatado: Fonte: $12 \mathrm{pt}$ 
Anexo 1

HOSPITAL DAS CLÍNICAS DA FACULDADE DE MEDICINA DA UNIVERSIDADE DE SÃO PAULO-HCFMUSP

MODELO DE TERMO DE CONSENTIMENTO LIVRE E ESCLARECIDO

I. DADOS DE IDENTIFICAÇÃO DO SUJEITO DA PESQUISA OU RESPONSÁVEL LEGAL

1. NOME:

DOCUMENTO DE IDENTIDADE № : SEXO： .M $\square$ F $\square$

DATA NASCIMENTO

ENDEREÇO

№

APTO:

BAIRRO

CIDADE

CEP:

TELEFONE: DDD

2. RESPONSÁVEL LEGAL

NATUREZA (grau de parentesco, tutor, curador etc.)

DOCUMENTO DE IDENTIDADE SEXO: M $\square F \square$

DATA NASCIMENTO

ENDEREÇO:

№

APTO:

BAIRRO:

CIDADE:

CEP TELEFONE: DDD

II. DADOS SOBRE A PESQUISA

\section{TÍTULO DO PROTOCOLO DE PESQUISA}

Uma versus sete sessões de Terapia de Aceitação e Compromisso no tratamento da fobia de espaços fechados: ensaio clínico randomizado

PESQUISADOR EXECUTANTE : Karen Vogel 
CARGO/FUNÇÃO: Psicóloga INSCRIÇÃO CONSELHO REGIONAL № 06/69083

UNIDADE DO HCFMUSP: Instituto de Psiquiatria

AVALIAÇÃO DO RISCO DA PESQUISA:

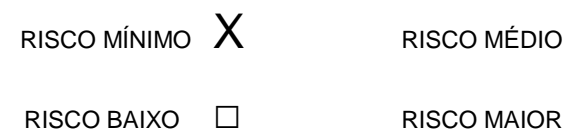

4. DURAÇÃO DA PESQUISA : 12 meses

\section{REGISTRO DAS EXPLICAÇÕES DO PESQUISADOR AO PACIENTE SOBRE A} PESQUISA CONSIGNADO

1. Justificativa e os objetivos da pesquisa; 2. Procedimentos que serão utilizados e propósitos, incluindo a identificação dos procedimentos que são experimentais; 3. Desconfortos e riscos esperados; 4. Benefícios que poderão ser obtidos; 5. Procedimentos alternativos que possam ser vantajosos para o indivíduo.

Ao assinar este documento você estará formalizando a sua intenção em participar de uma pesquisa que avaliará se o modelo terapêutico chamado de Terapia de Aceitação e Compromisso é eficaz no tratamento da fobia de espaços fechados (claustrofobia). Leia atentamente o texto abaixo e tire as dúvidas com a pesquisadora executante. Se você concordar em participar, você será submetido a alguns procedimentos conforme esclarecidos abaixo:

1. Inicialmente, você terá que vir a uma consulta aqui no hospital para a realização de questionários para avaliarem o seu grau de ansiedade e levantamento de outras informações pessoais como idade, endereço, história anterior da fobia de espaços fechados, etc.

2. Depois desta fase, você será chamado para iniciar as sessões da Terapia de Aceitação e Compromisso. Você poderá participar de uma até sete sessões desta terapia. Assim, você será chamado para comparecer ao hospital para as sessões nas datas combinadas entre você e a pesquisadora. Você poderá ser chamado de um até três dias para comparecer ao hospital. 
3. Como parte final da pesquisa, levaremos você até um simulador de Ressonância Magnética, que é um aparelho igual ao original, mas que não produz imagens. Ele foi elaborado para que pessoas com medo de espaços fechados pudessem treinar o exame antes de realizá-lo definitivamente, no aparelho real.

4. Ao término da pesquisa, os mesmos questionários utilizados no primeiro dia serão aplicados novamente.

5. Após três meses do final da sua participação na pesquisa, você será chamado para comparecer ao hospital para refazer os questionários que utilizamos no primeiro dia da sua participação na pesquisa.

Com estes procedimentos, você estará aumentando seus conhecimentos sobre algo que causa muito sofrimento para você (o medo de espaços fechados). Além disso, será importante você concluir o exame de Ressonância Magnética para que seu médico possa fazer um diagnóstico sobre sua saúde. Assim, você aprenderá a lidar com a ansiedade, o que poderá ajudá-lo (a) na realização tanto de outros exames de Ressonância Magnética quanto em outras situações de sua vida.

\section{ESCLARECIMENTOS DADOS PELO PESQUISADOR SOBRE GARANTIAS DO SUJEITO DA PESQUISA}

1. Acesso, a qualquer tempo, sobre as informações dos procedimentos, riscos e benefícios relacionados à pesquisa, inclusive para esclarecer dúvidas;

2. Liberdade de retirar seu consentimento a qualquer momento e de deixar de participar do estudo, sem que isso traga prejuízo à continuidade da assistência; 3. Salvaguarda da confidencialidade, sigilo e privacidade;

4. Disponibilidade de assistência no HCFMUSP, por eventuais danos à saúde, decorrentes da pesquisa.

Você não é obrigado a participar desta pesquisa, não havendo qualquer forma de repressão com a sua recusa. Deve ficar claro ainda que, em qualquer momento durante o andamento da pesquisa, você tem o direito de ser esclarecido quanto as suas dúvidas e inclusive de abandonar a pesquisa e mudar de ideia. Caso isso aconteça, seu tratamento não será interrompido e nem prejudicado. 
A assistência a eventuais consequências danosas a sua saúde que sejam decorrentes dos procedimentos realizados nesta pesquisa serão de responsabilidade de nossa equipe. Os dados pessoais fornecidos serão sigilosos e privados durante a pesquisa e após o termino da mesma.

\section{INFORMAÇÕES DE NOMES, ENDEREÇOS E TELEFONES DOS RESPONSÁVEIS PELO ACOMPANHAMENTO DA PESQUISA, PARA CONTATO EM CASO DE INTERCORRÊNCIAS:}

Qualquer dúvida ou colocação entrar em contato com:

Psic. Karen Vogel, R. Dr. Ovídio Pires de Campos, s/n - Pinheiros SP - telefone (11) 991439655 e e-mail: karen@ibmind.com.br

Dr. Francisco Lotufo Neto, R. Dr. Ovídio Pires de Campos, s/n Pinheiros SP - Telefone (11) 30696988 e e-mail: franciscolotufo@uol.com.br

Acredito ter sido suficientemente informado a respeito das informações que li ou que foram lidas para mim, descrevendo o estudo "Uma versus sete sessões de Terapia de Aceitação e Compromisso no tratamento da fobia de espaços fechados: ensaio clínico randomizado".

Eu discuti com a psicóloga Karen Camargo sobre a minha decisão em participar nesse estudo. Ficaram claros para mim quais são os propósitos do estudo, os procedimentos a serem realizados, seus desconfortos e riscos, as garantias de confidencialidade e de esclarecimentos permanentes. Ficou claro também que minha participação é isenta de despesas e que tenho garantia do acesso a tratamento hospitalar quando necessário. Concordo voluntariamente em participar deste estudo e poderei retirar o meu consentimento a qualquer momento, antes ou durante o mesmo, sem penalidades ou prejuízo ou perda de qualquer benefício que eu possa ter adquirido, ou no meu atendimento neste serviço. 
Assinatura do paciente/representante legal Data

\section{(Somente para o responsável do projeto)}

Declaro que obtive de forma apropriada e voluntária o Consentimento Livre e Esclarecido deste paciente ou representante legal para a participação neste estudo.

Data 
ANEXO 2

Dados Pessoais:

\begin{tabular}{|l|l|}
\hline Nome & \\
\hline Número & \\
\hline Sexo & \\
\hline Telefone & \\
\hline Naturalidade & \\
\hline Raça & \\
\hline Profissão & \\
\hline Estado Civil & \\
\hline Religião & \\
\hline Natural de & \\
\hline Escolaridade & \\
\hline Situação empregatícia & \\
\hline Renda familiar (salários mínimos) & \\
\hline & \\
\hline
\end{tabular}

\section{CheckList Geral}

\begin{tabular}{|l|l|}
\hline Item & OK \\
\hline Idade entre 18 e 60 anos & \\
\hline Sem risco suicídio & \\
\hline Sem comportamento automutilação & \\
\hline Psicose não estabilizada com medicação & \\
\hline $\begin{array}{l}\text { Risco clínico que impeça realização terapia / } \\
\text { exposição }\end{array}$ & \\
\hline Diagnóstico de fobia espaços fechados & \\
\hline Realizou MRI anterior? & \\
\hline Concluiu o exame? & \\
\hline & \\
\hline
\end{tabular}

\section{Entrevista sobre fobia}

1. Você já teve algum problema de saúde em sua vida? Qual? Idade? Detalhes?

2. Você já sofreu algum problema mental, psiquiátrico ou psicológico? 


\begin{tabular}{|l|l|l|l|l|}
\hline Qual problema? & Tratou? & Qual medicação? & Parou qual motivo? & Como evoluiu \\
\hline & & & & \\
\hline & & & & \\
\hline
\end{tabular}

3. Durante o último mês:

a) Pensou que seria melhor estar morto ou desejou estar morto? ( ) sim ( ) não

b) Quis fazer mal a si mesmo? ( ) sim ( ) não

c) Pensou em suicídio? ( ) sim ( ) não

d) Pensou numa maneira de se suicidar?( ) sim ( ) não

e) Tentou o suicídio?( ) sim ( ) não

f) Já fez alguma tentativa de suicídio?( ) sim ( ) não

4. Já sentiu vontade de autoferir-se? (cortar-se, queimar-se, machucar-se)? ( ) sim ( ) não

5. Alguma vez acreditou que alguém o espionava ou estava conspirando contra você ou tentando Ihe fazer algum mal? ( ) sim ( ) não

Se sim, atualmente pensa nisso? ( ) sim ( ) não

6. Alguma vez acreditou que alguém poderia ler ou ouvir seus pensamentos ou que você poderia ler ou ouvir os pensamentos de outra pessoa? ( ) sim ( ) não

Se sim, atualmente pensa nisso? ( ) sim ( ) não

7. Alguma vez acreditou que alguém ou alguma força exterior colocava, dentro da sua cabeça, pensamentos estranhos que não eram seus ou o fazia agir de modo diferente do seu jeito habitual? ( ) sim ( ) não

Se sim, atualmente pensa nisso? ( ) sim ( ) não

8. Alguma vez pensou que estava possuído? ( ) sim ( ) não

Se sim, atualmente pensa nisso? ( ) sim ( ) não

9. Alguma vez acreditou que estava recebendo mensagens especiais através da televisão, do rádio ou do jornal ou teve a impressão de que alguém que você não conhecia pessoalmente estava particularmente interessado em você? ( ) sim ( ) não

Se sim, atualmente pensa nisso? ( ) sim ( ) não

10. Existe alguém na sua família com diagnóstico de fobia de espaços fechados (realizado por médico)? ( ) sim ( ) não

11. Existe alguém na família com sintomas parecidos com os seus mas que nunca procurou tratamento?

12. Existe alguém na sua família com algum outro problema psiquiátrico (depressão, transt. pânico, esquizofrenia, transtono bipolar, bulimia, anorexia, outro)? 
13. Existe alguém na sua família com algum tipo de fobia (espaços fechados, altura, insetos, etc)? Qual?

14. Existe alguma coisa da qual você tem tido medo especial como voar, ver sangue, tomar uma injeção, alturas, lugares fechados ou certos tipos de animais ou insetos?

15. O que você tinha medo que pudesse acontecer quando estivesse em um local fechado?

16. Você sempre se sentiu assustado (a) quando você estava em locais fechados?

17. Você acha que você tem mais medo de locais fechados do que você deveria ter (medo excessivo ou irracional)?

18. Você chega a evitar locais fechados?

19. Existem coisas que você não faz por causa desse medo e que, caso contrário, teria feito?

Se não, o quanto é ou foi difícil para você ficar em locais fechados? Até que ponto o fato de que você tinha medo de espaços fechados incomoda ou incomodava você?

Se sim, até que ponto o medo de espaços fechados interfere na sua vida?

20. Você já realizou exame de R. M. anteriormente?

21. Se sim, quais foram suas sensações e pensamentos?

22. Se não, quais os pensamentos e sensações que você tem sobre o exame? 
ANEXO 3

\section{Questionário sobre Claustrofobia}

INSTRUÇÕES. As afirmações a seguir se referem a situações com as quais as pessoas podem ser deparar no dia a dia. Por favor, pedimos que leia atentamente cada uma delas e indique o quanto você se sentiria ansioso caso se encontrasse em tais circunstâncias. Saiba que não existem respostas certas ou erradas; queremos apenas conhecê-lo um pouco mais. Para tanto, pedimos que circule o número que melhor expressa seu grau de ansiedade, segundo a escala que se apresenta ao lado de cada afirmação.

\begin{tabular}{|c|c|c|c|c|c|}
\hline Frases / Situações & Nada ansioso & $\begin{array}{l}\text { Levemente } \\
\text { ansioso }\end{array}$ & $\begin{array}{l}\text { Moderadame } \\
\text { nte ansioso }\end{array}$ & $\begin{array}{l}\text { Muito } \\
\text { ansioso }\end{array}$ & $\begin{array}{l}\text { Extremamente } \\
\text { ansioso }\end{array}$ \\
\hline $\begin{array}{l}\text { 01. Nadar enquanto usa um } \\
\text { tampão de nariz. }\end{array}$ & 0 & 1 & 2 & 3 & 4 \\
\hline $\begin{array}{l}\text { 02. Trabalhar embaixo de uma } \\
\text { pia por } 15 \text { minutos. }\end{array}$ & 0 & 1 & 2 & 3 & 4 \\
\hline $\begin{array}{l}\text { 03. Estar em um elevador no } \\
\text { andar térreo com as portas } \\
\text { fechadas. }\end{array}$ & 0 & 1 & 2 & 3 & 4 \\
\hline $\begin{array}{l}\text { 04. Tentar pegar fôlego durante } \\
\text { exercício vigoroso. }\end{array}$ & 0 & 1 & 2 & 3 & 4 \\
\hline $\begin{array}{l}\text { 05. Ter um resfriado forte e } \\
\text { achar dificuldade para } \\
\text { respirar através do nariz. }\end{array}$ & 0 & 1 & 2 & 3 & 4 \\
\hline $\begin{array}{l}\text { 06. Respirar através de um tubo } \\
\text { de oxigênio em um } \\
\text { exercício seguro, num } \\
\text { tanque, por } 15 \text { minutos. }\end{array}$ & 0 & 1 & 2 & 3 & 4 \\
\hline $\begin{array}{l}\text { 07. Usar uma máscara de } \\
\text { oxigênio. }\end{array}$ & 0 & 1 & 2 & 3 & 4 \\
\hline $\begin{array}{l}\text { 08. Descansar na cama de baixo } \\
\text { de um beliche. }\end{array}$ & 0 & 1 & 2 & 3 & 4 \\
\hline $\begin{array}{l}\text { 09. Estar no meio da } 3^{\text {a }} \text { fileira } \\
\text { durante a realização de um } \\
\text { concerto em que você não } \\
\text { pode sair até o fim. }\end{array}$ & 0 & 1 & 2 & 3 & 4 \\
\hline $\begin{array}{l}\text { 10. No meio de uma fileira } \\
\text { cheia no cinema. }\end{array}$ & 0 & 1 & 2 & 3 & 4 \\
\hline $\begin{array}{l}\text { 11. Trabalhar embaixo de um } \\
\text { carro por } 15 \text { minutos. }\end{array}$ & 0 & 1 & 2 & 3 & 4 \\
\hline $\begin{array}{l}\text { 12. No ponto mais distante da } \\
\text { saída de um metrô em uma } \\
\text { excursão. }\end{array}$ & 0 & 1 & 2 & 3 & 4 \\
\hline $\begin{array}{l}\text { 13. Descansar numa sauna por } \\
15 \text { minutos. }\end{array}$ & 0 & 1 & 2 & 3 & 4 \\
\hline $\begin{array}{l}\text { 14. Esperar por } 15 \text { minutos, em } \\
\text { um avião, no chão, com as } \\
\text { portas fechadas. }\end{array}$ & 0 & 1 & 2 & 3 & 4 \\
\hline 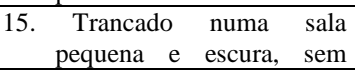 & 0 & 1 & 2 & 3 & 4 \\
\hline
\end{tabular}




\begin{tabular}{|c|c|c|c|c|c|}
\hline janelas por 15 minutos. & & & & & \\
\hline $\begin{array}{l}\text { Trancada numa sala } \\
\text { pequena e bem iluminada, } \\
\text { sem janelas por } 15 \\
\text { minutos. }\end{array}$ & 0 & 1 & 2 & 3 & 4 \\
\hline 17. Algemado por 15 minutos. & 0 & 1 & 2 & 3 & 4 \\
\hline $\begin{array}{l}\text { 18. Amarrado com as mãos } \\
\text { para trás por } 15 \text { minutos. }\end{array}$ & 0 & 1 & 2 & 3 & 4 \\
\hline $\begin{array}{l}\text { 19. Estar com uma roupa muito } \\
\text { apertada e incapaz de } \\
\text { removê-la. }\end{array}$ & 0 & 1 & 2 & 3 & 4 \\
\hline $\begin{array}{l}\text { 20. Estar numa camisa de } \\
\text { forças por } 15 \text { minutos. }\end{array}$ & 0 & 1 & 2 & 3 & 4 \\
\hline $\begin{array}{l}\text { 21. Deitar num saco de dormir } \\
\text { apertado incluindo pernas } \\
\text { e braços, amarrado no } \\
\text { pescoço, incapaz de sair } \\
\text { por } 15 \text { minutos. }\end{array}$ & 0 & 1 & 2 & 3 & 4 \\
\hline $\begin{array}{l}\text { 22. Apenas a cabeça dentro de } \\
\text { um saco de dormir com } \\
\text { fecho ecler fechado, capaz } \\
\text { de sair quando quiser. }\end{array}$ & 0 & 1 & 2 & 3 & 4 \\
\hline $\begin{array}{l}\text { 23. Deitar no porta mala de um } \\
\text { carro com o ar circulando } \\
\text { livremente por } 15 \text { minutos. }\end{array}$ & 0 & 1 & 2 & 3 & 4 \\
\hline $\begin{array}{l}\text { 24. Ter suas pernas amarradas } \\
\text { em uma cadeira imóvel. }\end{array}$ & 0 & 1 & 2 & 3 & 4 \\
\hline $\begin{array}{l}\text { 25. Trancado em um banheiro } \\
\text { público lotado. }\end{array}$ & 0 & 1 & 2 & 3 & 4 \\
\hline $\begin{array}{l}\text { 26. Num trem lotado com } \\
\text { escalas entre as estações. }\end{array}$ & 0 & 1 & 2 & 3 & 4 \\
\hline
\end{tabular}


ANEXO 4

\section{IDATE - ESTADO}

Nome:

Data

PARTE I

Leia cada pergunta e faça um círculo ao redor do número à direita da afirmação que melhor indicar como você se sente agora, neste momento.

Não gaste muito tempo numa única afirmação, mas tente dar uma resposta que mais se aproxime de como você se sente neste momento.

\section{AVALIAÇÃO}

Muitíssimo.........................

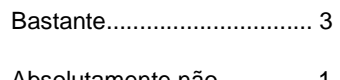

Absolutamente não............... 1

Sinto-me seguro(a)

$\begin{array}{llll}1 & 2 & 3 & 4\end{array}$

Estou tenso(a)

Estou arrependido

234

Sinto-me a vontade

$\begin{array}{llll}1 & 2 & 3 & 4\end{array}$

$\begin{array}{llll}1 & 2 & 3 & 4\end{array}$

Sinto-me perturbado(a)

234

Estou preocupado(a) com possíveis infortúnios

$\begin{array}{llll}1 & 2 & 3 & 4\end{array}$

Sinto-me descansado(a)

$\begin{array}{llll}1 & 2 & 3 & 4\end{array}$

Sinto-me ansioso(a)

Sinto-me "em casa"

$\begin{array}{lll}2 & 3 & 4\end{array}$

$\begin{array}{llll}1 & 2 & 3 & 4\end{array}$

$\begin{array}{llll}1 & 2 & 3 & 4\end{array}$

Sinto-me confiante

$\begin{array}{lll}2 & 3 & 4\end{array}$

Sinto-me nervoso(a)

Estou agitado(a)

$\begin{array}{llll}1 & 2 & 3 & 4\end{array}$

Sinto-me uma pilha de nervos

$\begin{array}{llll}1 & 2 & 3 & 4\end{array}$

Estou descontraído(a)

Sinto-me satisfeito(a)

$\begin{array}{llll}1 & 2 & 3 & 4\end{array}$

$\begin{array}{llll}1 & 2 & 3 & 4\end{array}$

$\begin{array}{llll}1 & 2 & 3 & 4\end{array}$

$\begin{array}{llll}1 & 2 & 3 & 4\end{array}$

Sinto-me superexcitado(a) e confuso(a)

1234

Sinto-me alegre

$\begin{array}{llll}1 & 2 & 3 & 4\end{array}$ 


\section{IDATE TRAÇO}

\section{PARTE - II}

Leia cada pergunta e faça um círculo ao redor do número à direita da afirmação que melhor indicar como você em geral se sente.

Não gaste muito tempo numa única afirmação, mas tente dar uma resposta que mais se aproxime de como você em geral se sente.

\section{Sinto-me bem}

Canso-me facilmente

Tenho vontade de chorar

Gostaria de poder ser tão feliz quanto os outros parecem ser

Perco oportunidades porque não consigo tomar decisões rapidamente

Sinto-me descansado(a)

Sou calmo(a), ponderado(a) e senhor(a) de mim mesmo

Sinto que as dificuldades estão se acumulando de tal forma que não as consigo resolver

10

11
Preocupo-me demais com coisas sem importância

Sou feliz

Deixo-me afetar muito pelas coisas

Não tenho muita confiança em mim mesmo(a)

Sinto-me seguro(a)

Evito ter que enfrentar crises ou problemas

Sinto-me deprimido(a)

Estou satisfeito(a)

Às vezes, idéias sem importância me entram na cabeça e ficam me preocupando

Sou uma pessoa estável

Fico tenso(a) e perturbado(a) quando penso em meus problemas do momento
Levo os desapontamentos tão a sério que não consigo tirá-los da cabeça $\begin{array}{llll}1 & 2 & 3 & 4\end{array}$

$\begin{array}{llll}1 & 2 & 3 & 4\end{array}$

$\begin{array}{llll}1 & 2 & 3 & 4\end{array}$

$\begin{array}{llll}1 & 2 & 3 & 4\end{array}$

$\begin{array}{llll}1 & 2 & 3 & 4\end{array}$

$\begin{array}{llll}1 & 2 & 3 & 4\end{array}$

$\begin{array}{llll}1 & 2 & 3 & 4\end{array}$

$\begin{array}{llll}1 & 2 & 3 & 4\end{array}$

$\begin{array}{llll}1 & 2 & 3 & 4\end{array}$

$\begin{array}{llll}1 & 2 & 3 & 4\end{array}$

$\begin{array}{llll}1 & 2 & 3 & 4\end{array}$

$\begin{array}{llll}1 & 2 & 3 & 4\end{array}$

$\begin{array}{llll}1 & 2 & 3 & 4\end{array}$

$\begin{array}{llll}1 & 2 & 3 & 4\end{array}$

$\begin{array}{llll}1 & 2 & 3 & 4\end{array}$

$\begin{array}{llll}1 & 2 & 3 & 4\end{array}$

$\begin{array}{llll}1 & 2 & 3 & 4\end{array}$

$\begin{array}{llll}1 & 2 & 3 & 4\end{array}$

$\begin{array}{llll}1 & 2 & 3 & 4\end{array}$

$\begin{array}{llll}1 & 2 & 3 & 4\end{array}$ 
ANEXO 5

TABELA DE NÚMEROS ALEATÓRIOS

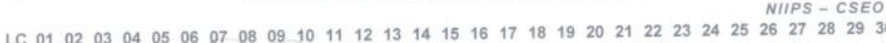

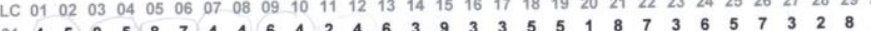
$\begin{array}{llllllllllllllllllllllllllllll}02 & 9 & 8 & 0 & 6 & 4 & 4 & 2 & 1 & 8 & 0 & 3 & 4 & 9 & 8 & 1 & 2 & 8 & 8 & 3 & 0 & 7 & 8 & 2 & 2 & 7 & 5 & 4 & 7 & 3\end{array}$ $\begin{array}{llllllllllllllllllllllllllllll}03 & 4 & 1 & 4 & 1 & 0 & 1 & 6 & 7 & 4 & 1 & 8 & 6 & 4 & 9 & 4 & 2 & 4 & 4 & 0 & 7 & 8 & 0 & 0 & 5 & 4 & 8 & 5 & 3 & 2\end{array}$ $\begin{array}{lllllllllllllllllllllllllllllll}04 & 7 & 4 & 4 & 9 & 5 & 1 & 0 & 6 & 7 & 3 & 9 & 3 & 2 & 5 & 4 & 2 & 8 & 8 & 5 & 3 & 8 & 7 & 8 & 1 & 1 & 8 & 7 & 5 & 9 & 4\end{array}$ $\begin{array}{lllllllllllllllllllllllllllllll}0 & 7 & 3 & 0 & 3 & 3 & 6 & 2 & 0 & 4 & 2 & 8 & 1 & 9 & 8 & 2 & 7 & 5 & 8 & 6 & 0 & 7 & 1 & 8 & 3 & 0 & 7 & 6 & 3 & 9 & 5\end{array}$ 0606 $\begin{array}{lllllllllllllllllllllllllllllll}07 & 8 & 5 & 3 & 8 & 1 & 6 & 6 & 7 & 8 & 1 & 3 & 3 & 7 & 1 & 5 & 3 & 1 & 6 & 2 & 8 & 8 & 7 & 2 & 1 & 3 & 6 & 9 & 0 & 8 & 1\end{array}$ $\begin{array}{lllllllllllllllllllllllllllllll}08 & 3 & 5 & 5 & 0 & 7 & 2 & 1 & 3 & 3 & 3 & 0 & 7 & 1 & 5 & 3 & 7 & 2 & 3 & 1 & 4 & 9 & 2 & 3 & 4 & 5 & 1 & 4 & 9 & 3 & 9\end{array}$ $\begin{array}{llllllllllllllllllllllllllllllll}09 & 2 & 9 & 6 & 3 & 8 & 1 & 2 & 1 & 0 & 8 & 5 & 7 & 1 & 4 & 9 & 5 & 6 & 3 & 7 & 6 & 2 & 4 & 7 & 4 & 0 & 5 & 6 & 1 & 7 \\ 10 & 6 & 6 & 8 & 4 & 4 & 7 & 4 & 8 & 4 & 6 & 9 & 7 & 2 & 7 & 4 & 5 & 1 & 7 & 5 & 2 & 0 & 2 & 5 & 8 & 1 & 1 & 6 & 2 & 0\end{array}$ $\begin{array}{llllllllllllllllllllllllllllll}14 & 6 & 2 & 2 & 7 & 8 & 8 & 8 & 2 & 0 & 3 & 9 & 9 & 3 & 5 & 1 & 5 & 0 & 5 & 9 & 5 & 9 & 2 & 2 & 3 & 2 & 8 & 4 & 4 & 2\end{array}$ $\begin{array}{lllllllllllllllllllllllllllllll}12 & 6 & 8 & 8 & 7 & 9 & 6 & 7 & 3 & 9 & 3 & 5 & 3 & 2 & 3 & 9 & 3 & 8 & 8 & 0 & 9 & 7 & 0 & 9 & 9 & 5 & 4 & 5 & 5 & 1 & 8\end{array}$ $\begin{array}{lllllllllllllllllllllllllllllll}13 & 7 & 8 & 2 & 8 & 9 & 3 & 2 & 0 & 7 & 5 & 9 & 0 & 6 & 7 & 0 & 6 & 6 & 2 & 5 & 3 & 4 & 5 & 2 & 2 & 0 & 9 & 7 & 4 & 7 & 1\end{array}$ $\begin{array}{lllllllllllllllllllllllllllllll}14 & 6 & 4 & 3 & 8 & 8 & 5 & 0 & 0 & 0 & 5 & 1 & 4 & 7 & 3 & 7 & 4 & 6 & 7 & 9 & 5 & 1 & 3 & 5 & 3 & 2 & 4 & 7 & 2 & 3 & 2\end{array}$ $\begin{array}{lllllllllllllllllllllllllllllll}15 & 3 & 6 & 1 & 1 & 7 & 8 & 3 & 9 & 6 & 3 & 2 & 6 & 1 & 8 & 8 & 3 & 7 & 8 & 9 & 2 & 9 & 3 & 8 & 7 & 3 & 5 & 8 & 7 & 2 & 6\end{array}$ $\begin{array}{lllllllllllllllllllllllllllllll}16 & 7 & 5 & 5 & 1 & 5 & 3 & 2 & 7 & 8 & 1 & 7 & 1 & 2 & 2 & 0 & 6 & 8 & 6 & 5 & 8 & 7 & 1 & 0 & 2 & 8 & 8 & 0 & 5 & 6 & 6\end{array}$ $\begin{array}{lllllllllllllllllllllllllllllll}17 & 8 & 8 & 8 & 1 & 5 & 9 & 7 & 6 & 2 & 5 & 5 & 2 & 8 & 8 & 1 & 9 & 0 & 0 & 5 & 9 & 2 & 0 & 1 & 3 & 9 & 8 & 6 & 3 & 2 & 5\end{array}$ $\begin{array}{lllllllllllllllllllllllllllllll}18 & 4 & 6 & 3 & 9 & 8 & 2 & 7 & 3 & 2 & 8 & 0 & 2 & 1 & 2 & 9 & 2 & 2 & 6 & 9 & 5 & 3 & 1 & 2 & 5 & 0 & 0 & 0 & 5 & 9 & 6\end{array}$ $\begin{array}{lllllllllllllllllllllllllllllll}19 & 4 & 0 & 6 & 5 & 1 & 7 & 6 & 7 & 1 & 0 & 3 & 1 & 9 & 3 & 7 & 7 & 0 & 0 & 9 & 2 & 9 & 3 & 8 & 1 & 6 & 5 & 5 & 5 & 0 & 9\end{array}$ $\begin{array}{llllllllllllllllllllllllllllll}20 & 5 & 8 & 0 & 9 & 3 & 4 & 7 & 7 & 0 & 5 & 4 & 1 & 5 & 1 & 8 & 3 & 4 & 3 & 8 & 3 & 9 & 6 & 6 & 7 & 7 & 2 & 3 & 2 & 5 \\ 21 & 0 & 5 & 8 & 1 & 2 & 0 & 4 & 5 & 5 & 8 & 0 & 0 & 4 & & 4 & 4 & 1 & 9 & 2 & 5 & 6 & 1 & 3 & 0 & 3 & 1 & 2 & 1 & 2\end{array}$ $\begin{array}{lllllllllllllllllllllllllllllllll}21 & 0 & 5 & 8 & 1 & 2 & 0 & 4 & 5 & 5 & 8 & 0 & 6 & 4 & 8 & 4 & 4 & 1 & 9 & 2 & 5 & 6 & 1 & 3 & 0 & 3 & 1 & 2 & 1 & 2\end{array}$ $22 \begin{array}{lllllllllllllllllllllllllllll}22 & 7 & 6 & 4 & 9 & 4 & 6 & 6 & 6 & 7 & 1 & 5 & 0 & 3 & 2 & 8 & 4 & 4 & 5 & 0 & 6 & 8 & 0 & 7 & 5 & 2 & 0 & 3 & 6\end{array}$

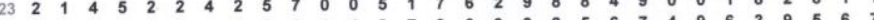
$\begin{array}{lllllllllllllllllllllllllllllllll}24 & 1 & 5 & 0 & 2 & 4 & 5 & 5 & 3 & 2 & 8 & 1 & 4 & 8 & 7 & 9 & 6 & 9 & 3 & 0 & 5 & 6 & 7 & 4 & 9 & 6 & 3 & 9 & 5 & 6\end{array}$ $\begin{array}{lllllllllllllllllllllllllllllll}25 & 8 & 6 & 0 & 2 & 8 & 0 & 9 & 1 & 2 & 5 & 0 & 7 & 1 & 0 & 2 & 1 & 9 & 9 & 5 & 6 & 5 & 8 & 7 & 8 & 0 & 0 & 9 & 0 & 1\end{array}$

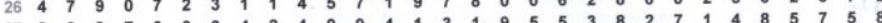

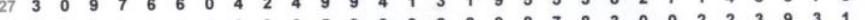

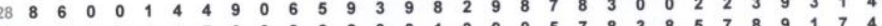

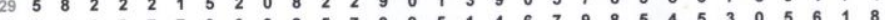

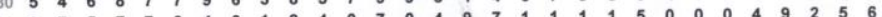
$\begin{array}{llllllllllllllllllllllllllllllllll}31 & 9 & 7 & 5 & 7 & 7 & 3 & 4 & 0 & 1 & 8 & 4 & 0 & 7 & 0 & 4 & 9 & 7 & & 4 & 1 & 1 & 5 & 0 & 0 & 0 & 4 & 9 & 2 & 5 & 0\end{array}$

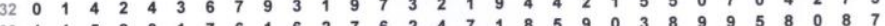

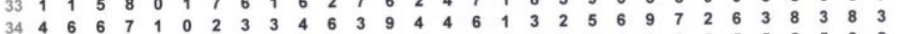

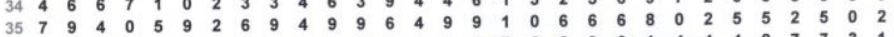
$\begin{array}{lllllllllllllllllllllllllllllll}36 & 5 & 5 & 6 & 0 & 6 & 2 & 4 & 6 & 7 & 1 & 5 & 6 & 1 & 1 & 8 & 4 & 7 & 6 & 2 & 9 & 6 & 1 & 4 & 4 & 4 & 8 & 7 & 7 & 3 & 1\end{array}$ $\begin{array}{llllllllllllllllllllllllllllll}37 & 9 & 3 & 6 & 0 & 6 & 7 & 0 & 1 & 9 & 1 & 3 & 2 & 9 & 0 & 7 & 7 & 9 & 6 & 4 & 4 & 5 & 4 & 2 & 8 & 3 & 6 & 0 & 7 & 4 \\ 7\end{array}$

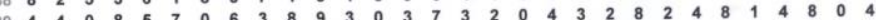

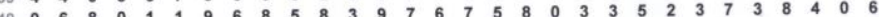

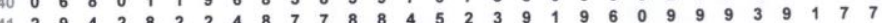

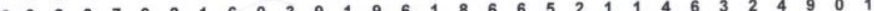
$\begin{array}{llllllllllllllllllllllllllllll}2 & 0 & 2 & 3 & 7 & 9 & 2 & 1 & 6 & 0 & 3 & 9 & 1 & 9 & 6 & 1 & 0 & 7 & 4 & 2 & 1 & 1 & 4 & 6 & 0 & 3 & 6 & 3 & 2 & 2\end{array}$

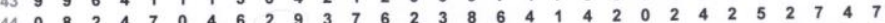

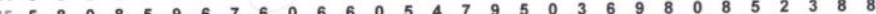

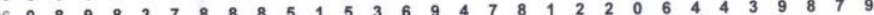

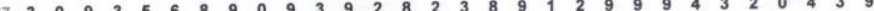

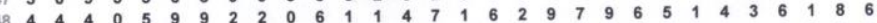

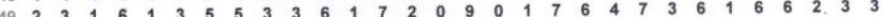

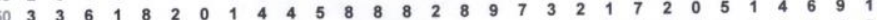

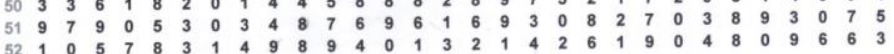
53 
ANEXO 6

Folha de Randomização

\begin{tabular}{|c|c|c|}
\hline Paciente & Grupo & Nome e telefone paciente \\
\hline 29 & A & \\
\hline 05 & $B$ & \\
\hline 21 & A & \\
\hline 15 & $B$ & \\
\hline 30 & $A$ & \\
\hline 01 & $B$ & \\
\hline 11 & A & \\
\hline 06 & $B$ & \\
\hline 02 & A & \\
\hline 08 & $B$ & \\
\hline 23 & A & \\
\hline 10 & B & \\
\hline 03 & A & \\
\hline 27 & B & \\
\hline 28 & A & \\
\hline 09 & $B$ & \\
\hline 22 & A & \\
\hline 24 & $B$ & \\
\hline 16 & A & \\
\hline 17 & B & \\
\hline 20 & A & \\
\hline 14 & $B$ & \\
\hline 13 & A & \\
\hline 04 & B & \\
\hline 26 & A & \\
\hline 25 & B & \\
\hline 18 & A & \\
\hline 07 & B & \\
\hline 19 & $\mathrm{~A}$ & \\
\hline 12 & $B$ & \\
\hline
\end{tabular}


ANEXO 7

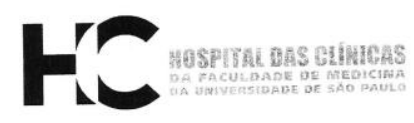

\section{APROVAÇÃO}

A Comissão de Ética para Análise de Projetos de Pesquisa CAPPesa da Diretoria Clínica do Hospital das Clínicas da Faculdade de Medicina da Universidade de São Paulo, em sessão de 11/05/2011. APROVOU ○ Protocolo de Pesquisa $n^{\circ}$ 0103/11, intitulado: "UMA VERSUS SETE SESSÕES DE TERAPIA DE ACEITAÇĀO E COMPROMISSO NO TRATAMENTO DA FOBIA DE ESPAÇOS FECHADOS: ENSAIO CLÍNICO RANDOMIZADO", apresentado pelo Departamento de PSIQUIATRIA, inclusive o Termo de Consentimento Livre e Esclarecido.

Cabe ao pesquisador elaborar e apresentar à CAPPesq, os relatórios parciais e final sobre a pesquisa (Resolução do Conselho Nacional de Saúde $n^{\circ} 196$, de 10/10/1996, inciso (X.2, letra "c").

Pesquisador (a) Responsável: Dr. Francisco Lotufo Neto

Pesquisador (a) Executante: Karen Vogel Ferreira de Camargo

CAPPesq, 12 de Maio de 2011

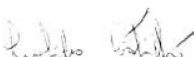

PROF. DR. EUCLIDES AYRES DE CASTILHO Coordenador

Comissão de Ética para Análise de Projetos de Pesquisa - CAPPesq

Comissåo de Ética para Análise de Projetos de Pesquisa do HCFMUSP da Diretoria Clinica do Hosphal das Clinicas da Faculdade de Medicina da Universidade de São Paulo Rua Ovidio Pires de Campos, 225, $5^{\circ}$ andar - CEP 05403010 - São Paulo - SP Fone: 01130696442 Fax: 01130696492

e-mail: cappesq@hcnet.usp.br 